\title{
ESTOQUE DE CAPITAL FIXO NO BRASIL: SÉRIES DESAGREGADAS ANUAIS, TRIMESTRAIS E MENSAIS
}

\author{
José Ronaldo de Castro Souza Júnior
}

Felipe Moraes Cornelio

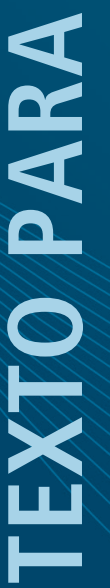





\section{TEXTO PARA DISCUSSÃO}

Rio de Janeiro, agosto de 2020

\section{ESTOQUE DE CAPITAL FIXO NO BRASIL: SÉRIES DESAGREGADAS ANUAIS, TRIMESTRAIS E MENSAIS}

José Ronaldo de Castro Souza Júnior ${ }^{2}$

Felipe Moraes Cornelio ${ }^{3}$

\footnotetext{
1. Os autores agradecem as contribuições de Ana Jordânia de Oliveira e Luciano Nakabashi, então bolsistas na Diretoria de Estudos e Políticas Macroeconômicas (Dimac) do Ipea; as sugestões de técnicos do Ipea, especialmente Eustáquio Reis e Marco Antônio Cavalcanti; e os pareceres das equipes do Departamento de Contas Nacionais do Instituto Brasileiro de Geografia e Estatística (IBGE) e da Secretaria de Desenvolvimento de Infraestrutura (do Ministério da Economia) e também dos participantes dos seminários em que versões preliminares deste texto foram apresentadas.

2. Diretor e técnico de planejamento e pesquisa na Dimac/lpea.

3. Pesquisador do Programa de Pesquisa para o Desenvolvimento Nacional (PNPD) na Dimac/lpea.
} 


\section{Governo Federal}

\section{Ministério da Economia}

Ministro Paulo Guedes

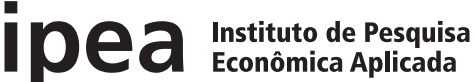

Fundação pública vinculada ao Ministério da Economia, o Ipea fornece suporte técnico e institucional às ações governamentais - possibilitando a formulação de inúmeras políticas públicas e programas de desenvolvimento brasileiros - e disponibiliza, para a sociedade, pesquisas e estudos realizados por seus técnicos.

Presidente

Carlos von Doellinger

Diretor de Desenvolvimento Institucional Manoel Rodrigues Junior

Diretora de Estudos e Políticas do Estado, das Instituições e da Democracia

Flávia de Holanda Schmidt

Diretor de Estudos e Políticas Macroeconômicas José Ronaldo de Castro Souza Júnior

Diretor de Estudos e Políticas Regionais, Urbanas e Ambientais

Nilo Luiz Saccaro Júnior

Diretor de Estudos e Políticas Setoriais de Inovação e Infraestrutura

André Tortato Rauen

\section{Diretora de Estudos e Políticas Sociais} Lenita Maria Turchi

Diretor de Estudos e Relações Econômicas e Políticas Internacionais Ivan Tiago Machado Oliveira

Assessora-chefe de Imprensa e Comunicação Mylena Fiori

\section{Texto para Discussão}

Publicação seriada que divulga resultados de estudos e pesquisas em desenvolvimento pelo Ipea com o objetivo de fomentar o debate e oferecer subsídios à formulação e avaliação de políticas públicas.

(C) Instituto de Pesquisa Econômica Aplicada - ipea 2020

Texto para discussão / Instituto de Pesquisa Econômica Aplicada.- Brasília : Rio de Janeiro : Ipea, 1990-

ISSN 1415-4765

1.Brasil. 2.Aspectos Econômicos. 3.Aspectos Sociais. I. Instituto de Pesquisa Econômica Aplicada.

CDD 330.908

DOI: http://dx.doi.org/10.38116/td2580

As publicações do Ipea estão disponíveis para download gratuito nos formatos PDF (todas) e EPUB (livros e periódicos). Acesse: http://www.ipea.gov.br/portal/publicacoes

As opiniões emitidas nesta publicação são de exclusiva e inteira responsabilidade dos autores, não exprimindo, necessariamente, o ponto de vista do Instituto de Pesquisa Econômica Aplicada ou do Ministério da Economia.

É permitida a reprodução deste texto e dos dados nele contidos, desde que citada a fonte. Reproduções para fins comerciais são proibidas. 


\section{SUMÁRIO}

SINOPSE

ABSTRACT

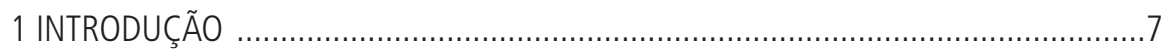

2 SÉRIES DE ESTOQUE DE CAPITAL ESTIMADAS PARA O BRASIL..............................

3 MÉTODO DO ESTOQUE PERPÉTUO …............................................................10

4 CONSTRUÇÃO DA SÉRIE HISTÓRICA DE INVESTIMENTO LÍQUIDO A

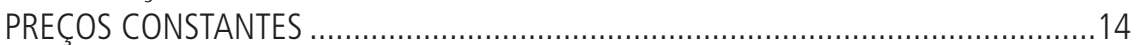

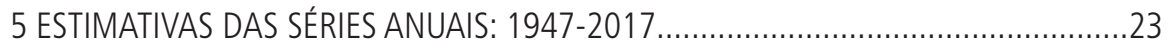

6 ESTIMATIVAS DE SÉRIES TRIMESTRAIS E MENSAIS DE INVESTIMENTO LÍQUIDO E ESTOQUE DE CAPITAL (1996-2019) .................................................31

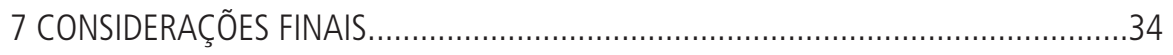

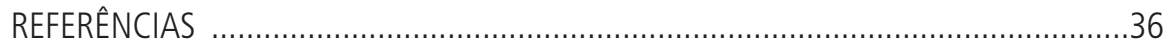

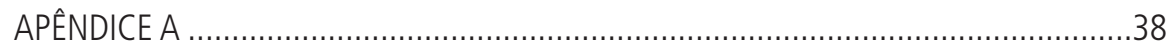

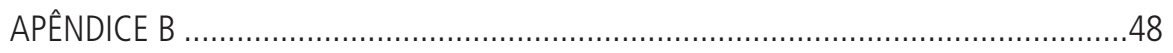

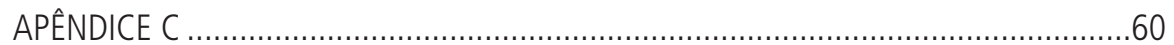





\section{SINOPSE}

A série histórica de estoque de capital é fundamental para estudos de crescimento econômico e para estimaçáo do produto potencial - variável muito utilizada em análises de política macroeconômica -, por meio da função de produção. Uma das principais contribuiçôes deste trabalho em relação aos já existentes é estimar o estoque de capital a partir de dados da Formação Bruta de Capital Fixo (FBCF) desagregados por produto utilizando um detalhado levantamento e tratamento de dados históricos. Isso faz com que possíveis distorções decorrentes de mudança nos preços relativos e de mudanças na composição do investimento sejam capturadas com maior precisão, e as estimativas da depreciação e do investimento líquido fiquem mais acuradas. Para se obter dados desagregados dessa forma, foi necessário adequar informaçōes de diferentes metodologias obtidas nas tabelas de recursos e usos (TRUs) e nas matrizes de insumo-produto (MIPs), bem como utilizar taxas de depreciação e tempo de vida útil em nível de produtos. Ao término, foram obtidas estimativas anuais das seguintes variáveis para o período de 1947 a 2017: estoque líquido de capital fixo; investimento líquido; taxa de investimento; taxa de depreciação; e relação capital/produto. Outra contribuição deste texto é a estimação de séries com frequências mais altas (trimestral e mensal), com dados atualizados até 2019 e compatíveis com o Sistema de Contas Nacionais (SCN) referência 2010, ampliando o escopo de aplicação das séries estimadas para análises de curto prazo da economia brasileira.

Palavras-chave: investimento; estoque de capital; Contas Nacionais.

\section{ABSTRACT}

Fixed Capital has a major role in economic growth literature and on the estimation of potential output using a production function - which is essential to design macroeconomic policy. One of the main contributions of this work, differently from the previous works, is to estimate the capital stock from a disaggregated perspective using Gross Fixed Capital Formation (GFCF) by product level throughout a detailed and historical treatment of the data from System of National Accounts (SNA). This methodology avoids distortions arise from changes in relative prices and changes in capital composition, capturing the real GFCF flows with precision and leading to better estimation of depreciation and net investment. In order to obtain a consistent and disaggregated time series of GFCF, it was necessary to adapt information from different methodologies obtained in the Supply and Uses Tables and in the Input-Output Tables (IO), as well as to use depreciation 
rates and life cycle in terms of products. At the end, annual estimates of the following variables were obtained for the period from 1947 to 2017: net fixed capital stock, net investment, investment rate, depreciation rate and capital/output ratio. Another contribution of this paper is the estimation of series with higher frequencies (quarterly and monthly), with data updated until 2019 and compatible with the SNA expanding the scope of application of the estimated series for short-run analysis.

Keywords: investment; capital stock; National Accounts. 


\section{INTRODUÇÃO}

O estoque de capital fixo é fundamental para estudos de crescimento econômico de longo prazo e para estimaçáo do produto potencial por ser o componente central de qualquer especificação da função de produção na literatura de crescimento econômico. Por conta disso, para que se tenha confiança nos resultados desses exercícios é crucial que a estimativa dos fatores de produçáo seja realizada da forma mais precisa possível, criando assim um importante insumo para qualquer diagnóstico ou proposiçáo de política econômica. As estimativas existentes para o Brasil, além de estarem defasadas em termos de base de dados, calculam o estoque de capital a partir de dados de Formação Bruta de Capital Fixo (FBCF) e de taxas de depreciaçấo agregados por categorias (construçấo, máquinas e equipamentos e outros). A principal contribuição deste trabalho em relação aos já existentes é usar os dados desagregados por produtos e não pelas categorias, o que resulta em uma melhor estimativa para o estoque de capital, tendo em vista que os produtos que compóem a FBCF apresentam taxas de depreciação e dinâmicas de preços heterogêneas. Além disso, essa forma de desagregação permite um melhor aproveitamento do conjunto mais detalhado de dados presente nas metodologias mais recentes do Sistema de Contas Nacionais (SCN), especialmente da referência 2010, divulgado pelo Instituto Brasileiro de Geografia e Estatística (IBGE), metodologia mais recente.

Para todo o período da série histórica estimada neste trabalho, 1947-2017, foram feitos esforços para usar a informação mais desagregada possível, por meio de pesquisa de bases de dados até mesmo em documentos históricos para dados mais antigos necessários para a acumulação do estoque do ano inicial. Desagregaçóes superiores ao nível das três categorias foram possíveis para o período de 1970 a 2017, com a utilização das tabelas de recursos e usos (TRUs), das matrizes de insumo-produto (MIPs) e das matrizes de relaçóes intersetoriais (MRIs), disponibilizadas pelo IBGE. A partir dessas informaçôes foi possível utilizar a FBCF por produto. Para o período de 1947 a 1969 seguiu-se a literatura existente, que calcula o estoque de capital com base em dados de FBCF por categorias. Já para valores anteriores a 1947 foi estimada a série de FBCF a partir de proxys para as três referidas categorias - lembrando que dos dados anteriores a 1947 foram usados apenas os de fluxo, a fim de estimar o estoque acumulado até o período analisado. 
Outro resultado desse esforço de pesquisa é a construção de séries históricas para outras variáveis macroeconômicas relevantes, entre as quais podemos citar: taxas de depreciação implícitas (agregada e por categorias), investimento líquido, taxa de investimento a preços constantes e relação capital/produto. $O$ primeiro item representaria a taxa de depreciação agregada da economia, tendo em vista que, na metodologia utilizada aqui, as taxas de depreciação são definidas exogenamente, produto a produto. Já o segundo item é obtido de forma direta, depois de construída a série de estoque de capital e calculada a diferença entre o estoque de capital atual e o do período anterior. $\mathrm{O}$ terceiro item é simplesmente a participação da FBCF no produto interno bruto (PIB) a preços constantes, ambos mensurados a preços do mesmo ano. Por fim, a relação capital/produto é a razão entre o estoque de capital e o produto, ambos também medidos na mesma base.

Uma última tarefa realizada foi desagregar temporalmente as séries anuais de 1996 a 2019 para as frequências trimestral e mensal a partir, respectivamente, das informaçôes do Sistema de Contas Nacionais Trimestrais (SCNT), do IBGE, e do Indicador Ipea mensal de FBCF (Carvalho e Ribeiro, 2017). Com a utilização desses indicadores foi possível estender as séries de estoque de capital e de investimento líquido para 2018 e 2019, preenchendo uma importante lacuna da série anual.

Além desta introdução, o trabalho é composto por mais seis seçóes. A próxima faz uma síntese da literatura sobre estoque de capital do Brasil, para que seja possível perceber as diferenças entre as estimativas feitas aqui com as já existentes. A terceira seção explica a escolha metodológica e apresenta a forma de cálculo pelo método do inventário perpétuo. A quarta seção descreve detalhadamente como foi calculada a série de investimento líquido a preços constantes. A quinta seção apresenta os resultados obtidos na frequência anual. A sexta seção é responsável por apresentar a metodologia e os resultados obtidos para a transformação da série anual em trimestral/mensal. Por fim, a última seção traz as considerações finais com um balanço acerca dos resultados obtidos.

\section{SÉRIES DE ESTOQUE DE CAPITAL ESTIMADAS PARA 0 BRASIL}

Na América do Sul, um dos primeiros trabalhos dedicados ao tema foi de Hofman (1992), que estimou o estoque de capital fixo para Argentina, Brasil, Chile, Colômbia, México 
e Venezuela para o período 1950-1989, utilizando o método de estoque perpétuo, o mais empregado para estimar estoques de capital para os países da Organização para a Cooperação e Desenvolvimento Econômico (OCDE). A atualização das séries dos seis países até 1994, além da estimação para o Equador, foi realizada em Hofman (2000). Os resultados encontrados indicam que todos os países, exceto a Colômbia, experimentaram, entre 1950 e 1973, uma elevação do estoque de capital em relaçáo ao dos Estados Unidos. Entre 1980 e 1994, ocorreram quedas significativas nos estoques de capital relativo da Argentina e da Venezuela, enquanto nos demais países a relação se manteve praticamente estável, com leve crescimento relativo para Brasil, Colômbia e México.

Marquetti (2000), por sua vez, ao estimar o estoque de capital fixo para a economia brasileira no período 1950-1998, utilizou os estudos de Hofman (1992; 2000) como base de comparação, considerando um tempo de vida útil de construção residencial e não residencial de cinquenta anos; e para máquinas, equipamentos e outros, de quatorze anos, além de uma função de depreciação geométrica. Para o autor, o estoque líquido de capital em construção não residencial ganhou importância relativa, no período analisado; o estoque de máquinas e equipamentos presenciou uma elevação relativa até 1980, apresentando tendência inversa a partir de 1998; e a relação produto-capital foi de 1,20, em 1950, passando para 0,43, em 1998.

Também pelo método do estoque perpétuo, Morandi e Reis (2004) estimaram o estoque de capital fixo no Brasil para o período de 1950 a 2002. Como o SCN disponibiliza dados de FBCF somente a partir de 1947, os autores buscaram outras fontes para construir a série. Por exemplo, entre 1901 e 1946, os dados de investimento na construção civil foram construídos a partir do consumo aparente de cimento, enquanto a proxy utilizada para investimento bruto em máquinas e equipamentos foi as exportaçóes de bens de capital dos principais exportadores para o Brasil entre 1901 e 1946.

De acordo com as estimativas de Morandi e Reis (2004), a relação capital/produto no Brasil passou de 1,8, em 1950, para 3,1, em 2002, com um pico de 3,3, em 1992. O período de maior crescimento do estoque líquido de capital fixo ocorreu entre 1973 e 1983, com destaque para as estruturas do setor empresarial e máquinas e equipamentos do setor privado. Em termos desagregados, considerando os anos inicial e final do 
estudo, as estruturas do setor privado passaram de $0,4 \%$ do PIB para $1,3 \%$ do PIB; as estruturas do governo, de $0,3 \%$ do PIB para $0,4 \%$ do PIB; e as residências, de $0,7 \%$ do PIB para $1,0 \%$ do PIB.

Morandi (2011) atualizou a série de estoque de capital elaborada em Morandi e Reis (2004), com o período estimado indo de 1947 a 2009. A autora utilizou dados provenientes do SCN do IBGE, com atualização metodológica, referência 2000, em relação aos dados usados no trabalho anterior. Uma alteração importante nas estimativas do SCN referência 2000 foi a redução da participação relativa do investimento em construçóes, posteriormente revertida com a introdução da metodologia mais recente do SCN referência 2010 - como será mostrado na seção 4.

\section{MÉTOdO DO ESTOQUE PERPÉTUO}

Para a estimação do estoque de capital no Brasil e em vários países, as principais dificuldades são em relação à disponibilidade, à qualidade e à comparabilidade intertemporal dos dados necessários. Em alguns países, como os Estados Unidos, existem estimativas diretas do estoque de capital para alguns períodos, o que torna a tarefa mais simples. Mesmo nesses casos, no entanto, existem problemas de medida na hora da coleta dos dados e na comparaçáo intertemporal, devido aos erros de avaliação do estoque e à inflação, especialmente quando os dados de estoque são desagregados. Este último problema mencionado se torna sério em períodos de alta inflação, como é o caso da história da economia brasileira em vários momentos, sobretudo no final dos anos 1970 até meados dos anos 1990, o que inviabiliza a utilização das medidas diretas feitas pelos censos econômicos - realizados pelo IBGE até os anos 1980 .

Como são poucos os países que possuem estimativas diretas do estoque de capital, o que é mais utilizado internacionalmente é o método do estoque perpétuo, pois ele é relativamente simples de ser empregado, desde que se tenha disponibilidade de séries de FBCF consistentes e longas. Esses dados sáo contabilizados no SCN, sendo este padronizado internacionalmente, o que facilita a comparação entre países. Por esse motivo, ele é recomendado pelo manual de mensuração do capital da OCDE (OECD, 2009) para as estimativas do estoque de capital dos seus países-membros.

10 
No arcabouço da contabilidade social, conforme apresentado por Feijó e Ramos (2013), o investimento no período $t$ é definido por:

$$
I_{b, t}=I_{l, t}+I_{\mathrm{r}, t}
$$

Em que $I_{b}$ é o investimento bruto, $I_{l}$ é o investimento líquido e $I_{r}$ é o investimento de reposição.

Mais precisamente, o investimento bruto equivale ao total destinado à $\mathrm{FBCF}$. Parte desse investimento, no entanto, é destinada à reposiçấo do capital depreciado isto é, a parte do capital fixo que é consumida e/ou perde eficiência ao longo do tempo -, compondo o investimento em reposição. Em termos agregados, podemos assumir uma taxa de depreciação $(\delta)$ que incide sobre o estoque de capital passado $\left(K_{t-1}\right)$ :

$$
I_{r, t}=\delta K_{t-1}
$$

Excluída essa parte, o restante é o que efetivamente amplia o estoque de capital e, consequentemente, a capacidade produtiva (denominada investimento líquido). Em outras palavras, o investimento líquido pode ser representado como a variaçáo do estoque de capital entre um período produtivo e outro. Logo,

$$
I_{l, t}=\Delta K_{t}=K_{t}-K_{t-1}
$$


Substituindo as equaçóes (2) e (3) em (1) e realizando algumas operaçóes, obtém-se o estoque de capital ao final do período, ${ }^{1}$ que é representado por:

$$
K_{t}=(1-\delta) K_{t-1}+I_{b, t}
$$

O estoque de capital de final de período em termos agregados é formado, então, pelo estoque de capital do período anterior depreciado, somado ao investimento bruto realizado no período atual. Lembrando que $K_{t-1}$ é formado pela mesma relação, podemos substituir recursivamente até obter:

$$
K_{t}=\left[\sum_{j=1}^{S}(1-\delta)^{j-1} * I_{b, t-j+1}\right]+(1-\delta)^{S} K_{t-S}
$$

Onde $S$ é um intervalo de tempo qualquer. Essa é a representação genérica da formação do $K_{t}$ em termos agregados.

De forma análoga, o método do estoque perpétuo ${ }^{2}$ (perpetual inventory methodPIM) estima o estoque bruto de capital fixo por meio da soma do investimento bruto, considerando o período estimado de vida útil do capital. Esse cálculo é realizado, idealmente, para cada tipo, produto ou equipamento de capital. Trata-se da aplicaçáo prática da fórmula genérica obtida em (4) e, consequentemente, em (5).

Assumindo um tempo de vida útil $\theta$ para um ativo de capital $i$ qualquer, temos que o estoque de capital anterior a $\theta$ períodos não interfere no estoque de capital atual por conta de sua obsolescência em relação aos investimentos mais novos, ou por "morte" decorrente do desgaste técnico. Ou seja, a equação (5) pode ser reduzida para:

1. 0 estoque de capital também pode ser mensurado, tal como está em Feijó e Ramos (2013), como o de início de período. Em termos metodológicos não existe diferença na obtenção do estoque de capital; haveria somente na escolha do período em que o estoque será contabilizado. Caso fosse adotado o estoque de capital de início do período, a definição correta seria: $K_{t}=(1-\delta) K_{t-1}+I_{b, t-1}$. Em termos práticos, seria simplesmente dizer que o estoque de capital do início do período $t$ equivale ao estoque de capital do final de período $t-1$.

2. Esta seção segue de maneira próxima a metodologia conforme exposta em Morandi e Reis (2004).

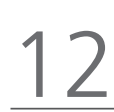




$$
K_{t}=\sum_{j=1}^{\ominus}(1-\delta)^{j-1} * I_{b, t-j+1}
$$

Para adequar a notação aqui adotada à literatura do PIM, o $K_{t}$ pode ser chamado de Estoque Líquido de Capital Fixo (ELCF), tendo em vista que a depreciaçáo do estoque passado está sendo retirada do estoque atual. Dessa forma, o ELCF de cada ativo $i$ em um período $t$ qualquer pode ser representado por:

$$
E L C F_{i, t}=\sum_{j=1}^{\theta_{i}}\left(1-\delta_{i}\right)^{j-1} * I_{b, i, t-j+1}
$$

Ou de forma semelhante:

$$
E L C F_{i, t}=E B C F_{i, t}-D_{i, t}
$$

Em que:

$$
\begin{aligned}
& E B C F_{t, i}=\sum_{j=1}^{\theta_{i}} I_{b, i, t-j+1} \\
& D_{i, t}=\sum_{j=2}^{\theta_{i}}\left[\left(\delta_{i}-1\right)^{j-1}+1\right] * I_{b, i, t-j+1}
\end{aligned}
$$

$\mathrm{O} E B C F_{t, i}$ representa o estoque bruto de capital fixo do ativo $i$ no período $t$. Por sua vez, $I_{b, j, i}$ é a soma do investimento bruto do ativo $i$ realizado no período $j$, que varia de acordo com a vida útil desse ativo $\left(\theta_{i}\right)$. Quando se retira do $E B C F_{i, t}$ a depreciaçáo total do capital no período considerado $\left(D_{i, t}\right)$, ou seja, o somatório da depreciaçáo de cada período, obtém-se a estimativa do $\operatorname{ELCF}\left(E L C F_{i, t}\right)$.

O estoque total de capital seria dado, entáo, pela soma do ELCF de cada ativo/produto/tipo de capital. Em termos algébricos, teríamos: 


$$
K_{t}=E L C F_{t}=\sum_{i=1}^{n} \sum_{j=1}^{\theta_{i}}\left(1-\delta_{i}\right)^{j-1} * I_{b, i, t-j+1}
$$

Uma hipótese fundamental desse método é a homogeneidade dos bens de capital considerados na equação (8). Os resultados da estimativa do estoque de capital são, portanto, mais confiáveis quando os dados estão contabilizados de forma mais desagregada por produto.

\section{CONSTRUÇÃO DA SÉRIE HISTÓRICA DE INVESTIMENTO LÍQUIDO A PREÇOS CONSTANTES}

A estratégia empregada aqui é usar as melhores informaçóes disponíveis para cada subperíodo, preferencialmente, de estatísticas oficiais. Para o subperíodo pós-1970, foi possível usar dados de FBCF por produtos, com um nível de detalhamento maior para os dados mais recentes. A depreciação e o deflacionamento dessas séries, por conseguinte, também foram calculados por produto. Para o período 1947-1969, utilizaram-se os dados de FBCF por componentes (construção, máquinas e equipamentos e outros) do SCN. Por último, para o período 1901-1946, foram usadas para se estimar as taxas de variação real dos investimentos brutos por componente variáveis proxy de fontes de dados alternativas. É bom lembrar que os dados pré-1947 são usados apenas para se estimar o estoque do período inicial. No final, é feita também uma desagregação da construção entre os seguintes subcomponentes: residencial, infraestrutura e outras estruturas.

\subsection{Composição da FBCF por produto (1970-2017)}

Conforme já discutido, a utilização de dados desagregados para estimativas de estoque de capital é preferível quando se adota o método do inventário-perpétuo, pois a deflação e a depreciação são feitas por produto e não por categoria. Isso faz com que possíveis distorçôes decorrentes de mudanças nos preços relativos e na composiçáo do investimento sejam capturadas com maior precisão, e as estimativas do estoque de capital fiquem mais acuradas. Para o período de 1970 a 2017, foi possível calcular a participaçáo de cada produto na FBCF com base em dados desagregados obtidos nas TRUs, MIPs e MRIs, seguindo a classificação de produtos vista em Hallak Neto e Forte (2016) - usada para a compatibilizaçáo dos produtos das diferentes metodologias.

14 
As fontes de dados usados para calcular a participação de cada produto na FBCF são as seguintes.

- 1970 e 1975: MRIs com 110 produtos e 50 produtos que são usados para investimentos em capital fixo. Classificação baseada em Menezes e Ortega (1991).

- 1980: MIPs com 136 produtos no total e 15 produtos que são usados como investimento. Os dados são compatíveis com o Sistema de Contas Nacionais Consolidadas (SCNC), calculado pela Fundação Getulio Vargas (FGV) para o período 1947-1985 e pelo IBGE para o período 1986-1989 com base no manual da Organização das Naçóes Unidas (ONU) de 1968 (UN, 1968).

- 1985: MIPs com 80 produtos no total e 15 produtos que são usados para FBCF. Dados compatíveis com o SCNC e o marco teórico de 1968 da ONU.

- 1990-1999: TRUs com 80 produtos e 14 produtos que são usados para FBCF. Dados do SCN referência 1985 (denominado originalmente Novo Sistema de Contas Nacionais), cuja referência metodológica é o System of National Accounts (SNA) 1993 (European Commission et al., 1993).

- 2000-2009: TRUs com 107 produtos e 23 produtos que são usados para FBCF. Dados compatíveis com a série retropolada do SCN referência 2010 e marco teórico do SNA 2008 (European Commission et al., 2009).

- 2010-2017: TRUs com 128 produtos e 30 produtos que são usados para FBCF. Dados compatíveis com o SCN referência 2010 e marco teórico do SNA 2008 (European Commission et al., 2009).

No quadro B.1 (apêndice B) é possível visualizar quais produtos compóem a FBCF e em que componente estão inseridos (máquinas e equipamentos, construção ou outros) para cada período de análise. A classificação dos produtos mostra três grandes grupos que apresentam grande similaridade na sua composição: os períodos 1970-1979, 1980-1999 e 2000-2017.

As séries desagregadas para os períodos 1971-1974, 1976-7979, 1981-1984 e 1986-1989 foram criadas ao se realizar uma interpolação linear dos dados, distribuindo, ano a ano, a participação de cada produto por componente da FBCF, partindo das MRIs de 1970 e 1975; MIPs de 1980 e 1985; e TRUs de 1990. Esses valores, usados com referências das participaçóes de cada produto, foram calculados com base nos dados já deflacionados, de acordo com procedimento que será explicitado mais à frente. As participaçôes obtidas pela interpolação foram aplicadas na mesma série agregada 
utilizada diretamente para o período 1947-1969, com o objetivo de manter consistência metodológica, ao menos para os valores totais.

\subsection{Comparação entre as referências 1985, 2000 e 2010 do SCN}

A definição das bases de dados originais que seriam utilizadas para encadear a série de FBCF - há períodos para os quais há mais de uma fonte disponível - é uma etapa crucial deste trabalho. Os gráficos 1, 2 e 3 comparam as séries de FBCF em valores correntes, em bilhões de reais, nas diferentes referências e mostram com clareza que seus dois componentes principais (construção e máquinas e equipamentos) do SCN referência 2010 (a metodologia mais recente do IBGE) se encaixam melhor com os dados do SCN referência 1985. Essa diferença de nível fica ainda mais explícita caso seja avaliada a composição da FBCF (gráfico 4). Tomando como a base a média da participação de cada categoria para o período de 2000 a 2002, em que existem informaçóes nas três referências, a discrepância da referência 2000 em relação às demais (1985 e 2010) fica ainda mais evidente. Embora a categoria outros tenha um comportamento distinto, de forma geral, o SCN referência 2010 é mais bem ajustado ao SCN referência 1985. Partindo dessas informaçóes, foi escolhido não usar os dados da referência 2000.

GRÁFICO 1

FBCF nas diferentes metodologias do SCN: construção (1995-2010)

(Em R\$ bilhões, a preços correntes)

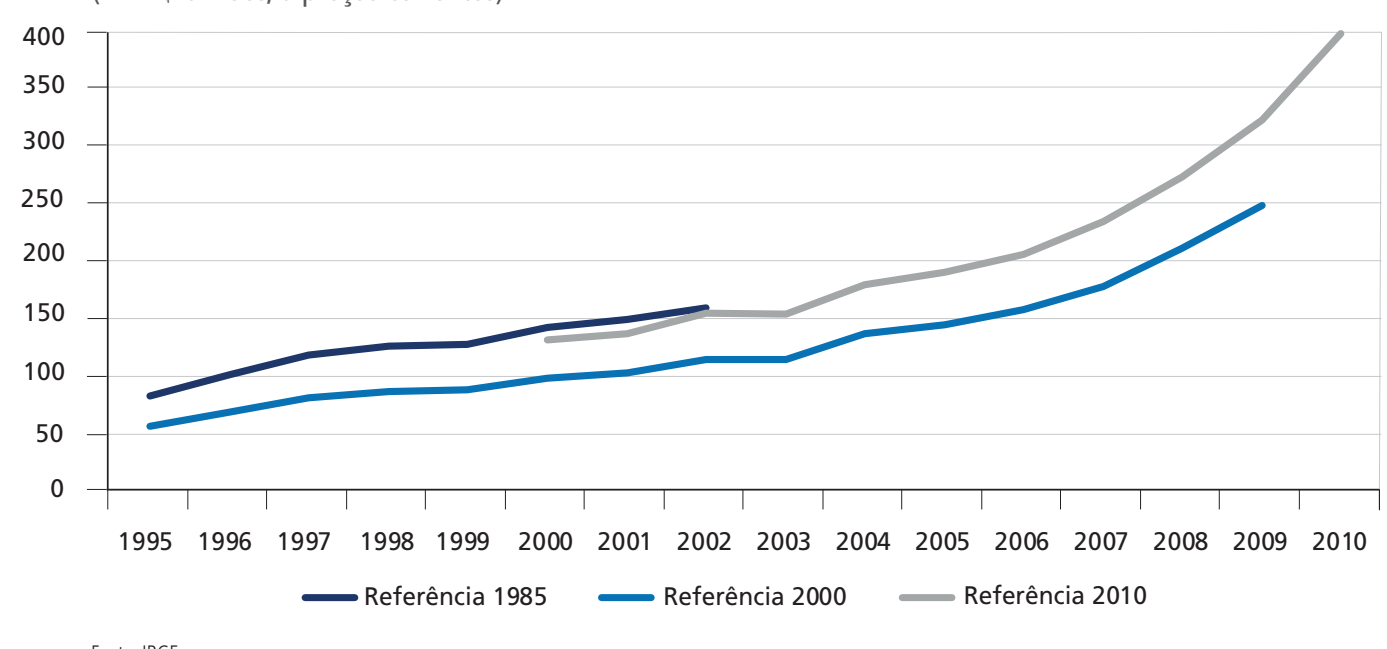

Fonte: IBGE. 
Texto para

Discussão

2580 Estoque de Capital Fixo no Brasil: séries desagregadas anuais, trimestrais e mensais

GRÁFICO 2

FBCF nas diferentes metodologias do SCN: máquinas e equipamentos (1995-2010)

(Em R\$ bilhões, a preços correntes)

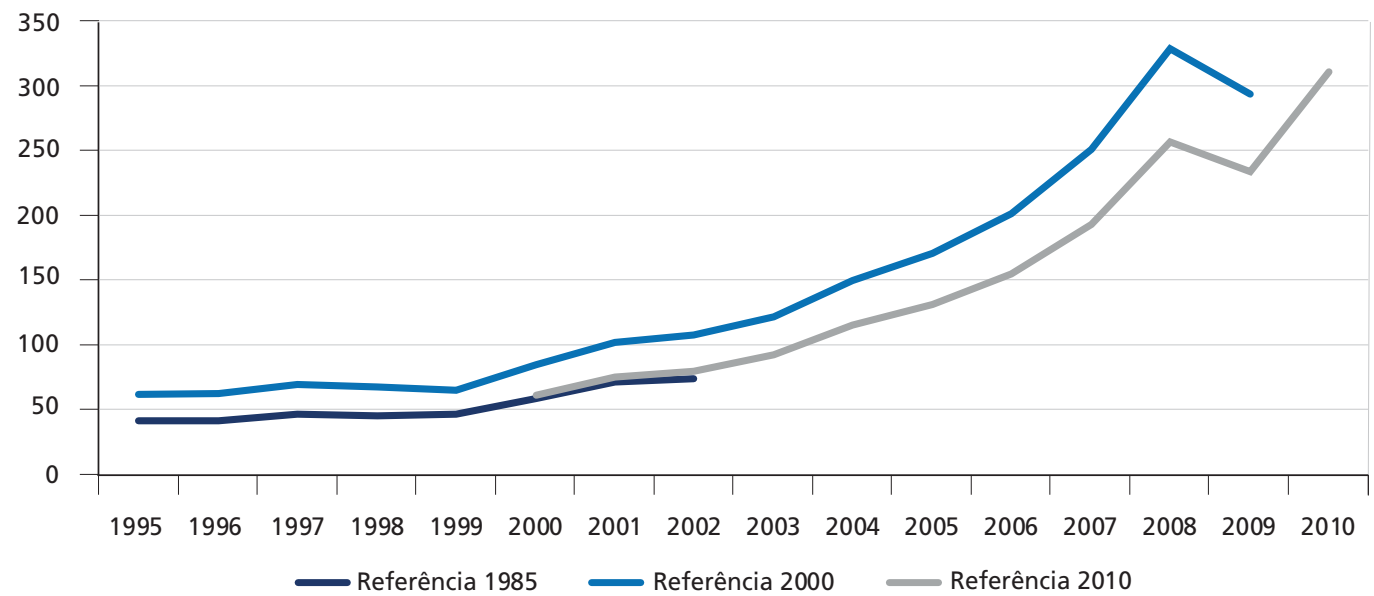

Fonte: IBGE.

GRÁFICO 3

FBCF nas diferentes metodologias do SCN: total (1995-2010)

(Em R\$ bilhões, a preços correntes)

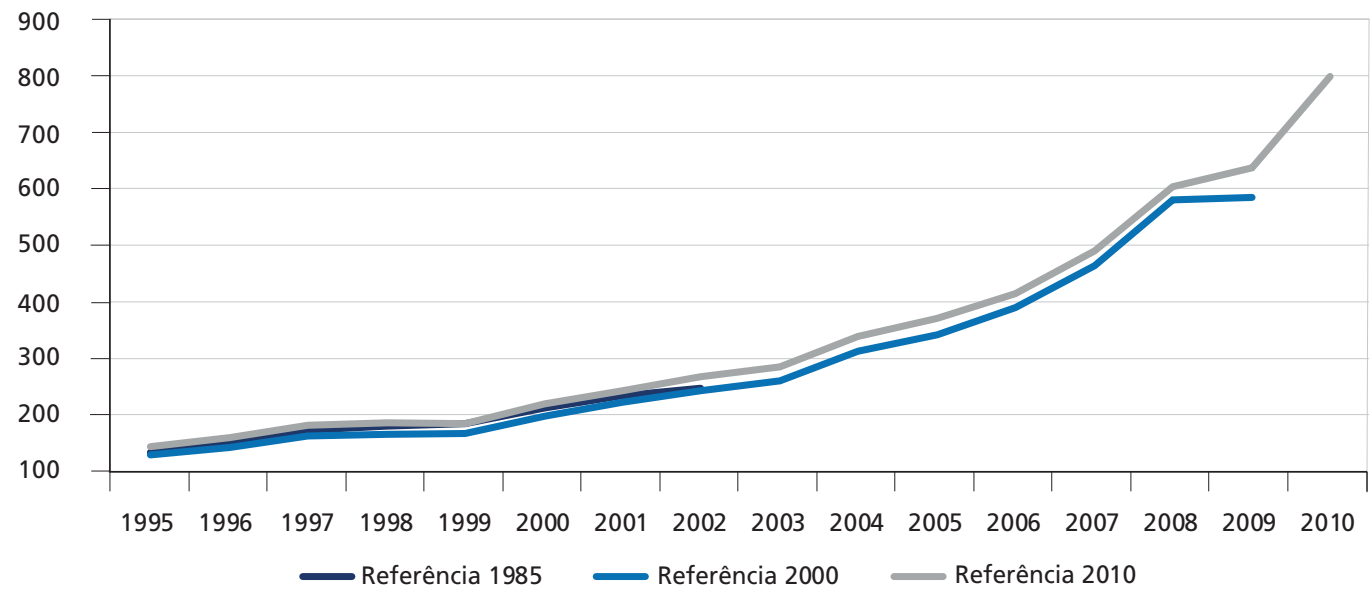

Fonte: IBGE. 


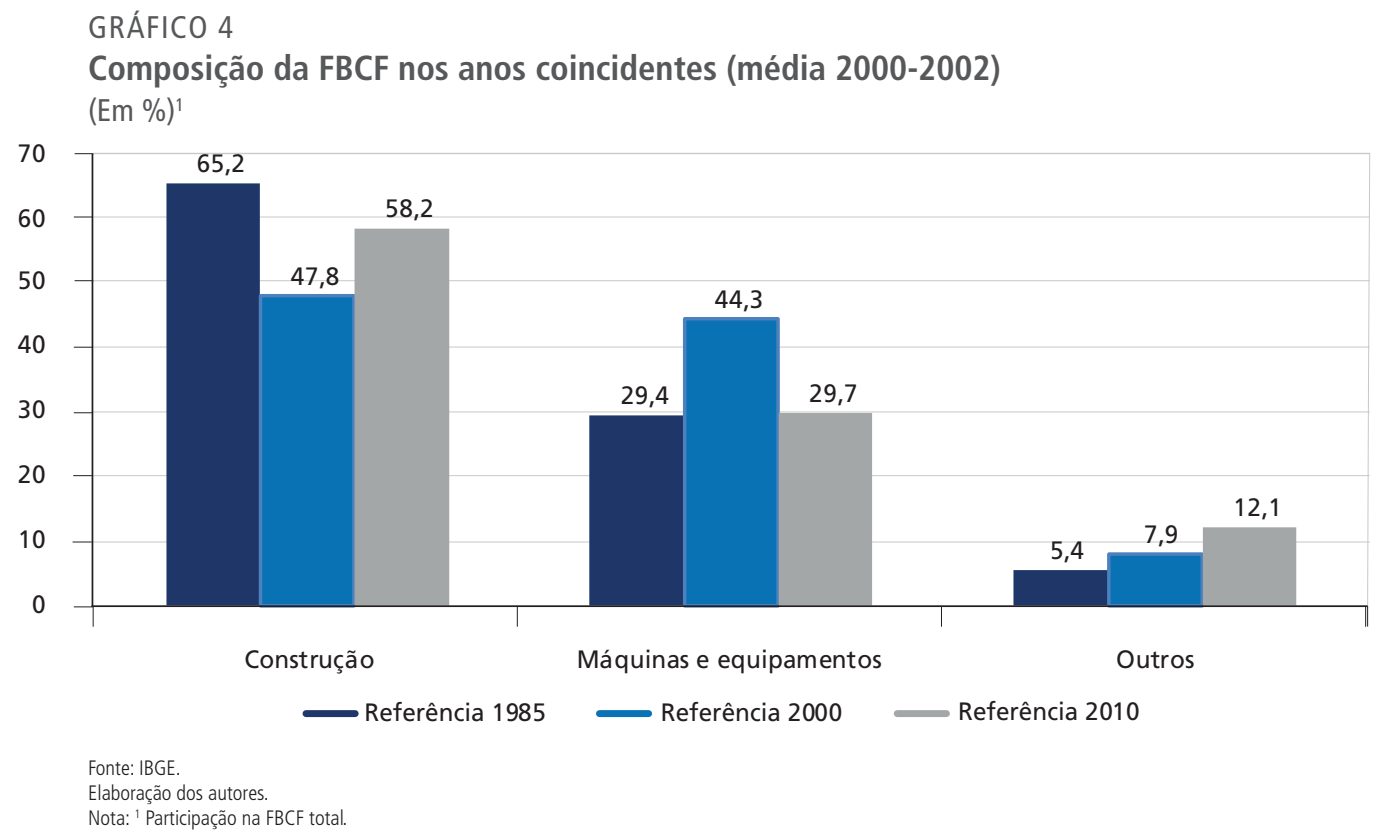

\subsection{Deflacionamento dos dados (1970-2017)}

\subsubsection{Deflatores desagregados para o período 2000-2017}

O primeiro passo para a criação dos deflatores é calcular a variação dos preços anuais e, posteriormente, estabelecer um ano-base - tal procedimento está descrito com mais detalhes no apêndice C. Optou-se por adotar 2010 como ano-base, pois é quando se promove o encaixe entre a série no nível divulgação do SCN referência 2010 e a sua série retropolada. Dessa forma, é possível obter deflatores de forma direta por produto para o período 2000-2017.

\subsubsection{Deflatores desagregados para o período 1970-1999}

As informações existentes nas MIPs e nas TRUs possibilitam a criação de deflatores em nível de produtos durante o período 1970-1999. Os produtos que compóem as Contas Nacionais nas metodologias anteriores, no entanto, diferem dos produtos que compóem o SCN referência 2010 (período 2000-2017), de modo que náo é possível deflacionar essa série diretamente. A seguir será explicada a forma como foi tratada a série para cada período/metodologia adotados. 
Para o período 1990-1999, os dados existentes se encontram no SCN referência 1985. A forma escolhida para calcular os deflatores foi encadear com os deflatores calculados para o ano 2000 obtidos na série retropolada do SCN referência 2010. A partir desse valor encadearam-se os deflatores para os produtos pela variação do nível de preços ano a ano obtidos pelos dados na referência 1985. Além disso, entre 1995 e 1999, o total da FBCF e as variaçóes reais foram ajustadas de forma a serem iguais às estimativas obtidas no SCNT, as quais são contabilizadas de acordo com o SCN referência 2010. Em outras palavras, os totais (e suas variaçóes reais) foram mantidos na referência 2010, e somente as participaçôes dos produtos na FBCF do SCN 1985 foram usadas no cálculo. $\mathrm{O}$ encadeamento foi baseado numa compatibilização entre os produtos de ambas as referências, de acordo com a sua similaridade (quadro B.2 no apêndice $\mathrm{B}$ ).

Para o período anterior a 1990 não há informaçóes desagregadas por produto em frequência anual. Existem apenas as MIPs (de 1985 e 1980) e as MRIs (de 1975 e 1970). Por isso, os deflatores obtidos em nível de produtos para 1990 foram encadeados pela variação ano a ano do componente ao qual o produto pertence (máquinas e equipamentos, construçáo ou outros). Sendo assim, os valores das MIPs de 1985 e 1980 e das MRIs de 1975 e 1970 foram deflacionados com base nos deflatores dos produtos encadeados pelas variações das três grandes categorias. As séries intermediárias (1989-1986; 1984-1981; 1979-1976; e 1974-1971) foram calculadas pela variação dos totais já deflacionados e não usaram de forma direta os deflatores.

\subsection{Estimativas da FBCF por componente para o período 1947-1969}

De 1947 a 1969, a série de FBCF foi construída utilizando dados da série histórica do SCNC - calculado pela FGV no período de 1947 a 1985 e pelo IBGE de 1986 a 1989 -, disponibilizada a valores correntes com periodicidade anual e devidamente convertida, neste trabalho, da moeda original para reais.

Para criar os deflatores desse período partiu-se dos valores usados em Morandi e Reis (2004), encadeando-os para frente até 2010 (ano-base deste trabalho). Originalmente, foram utilizadas as taxas de variação dos índices de preço específicos para cada categoria: i) em construção, utiliza-se o Índice Nacional de Custo da Construção (INCC); ii) em máquinas e equipamentos, utiliza-se o Índice de Preços ao Produtor Amplo - Disponibilidade Interna (IPA-DI) máquinas, equipamentos e veículos; e 
iii) em outros, utiliza-se o Índice de Preços ao Produtor Amplo - Oferta Global (IPA-OG) produtos agrícolas. No caso, os valores estavam com base em 1999 e terminavam em 2002. O encadeamento se deu a partir dos deflatores já calculados para o período de 2000 até 2010 neste trabalho. A última etapa foi mudar a base dos deflatores para 2010, resultando em deflatores de 1947 até 2010.

\subsection{Estimativas dos índices encadeados por componente da FBCF para o período anterior a 1947}

A principal fonte de informaçóes para a série de FBCF durante o período de 1901 a 1946 foi Villela e Suzigan (1973), em que podem ser encontradas diversas proxys para os componentes da FBCF. A seguir serão detalhadas as principais fontes de dados e a forma como o valor da FBCF foi calculado nos três componentes usuais: construção, máquinas e equipamentos e outros.

Para a elaboração do item construção, foi utilizado como proxy o consumo aparente de cimento de Villela e Suzigan (1973), que é fornecido em quantum (toneladas) de 1901 a $1946 .^{3}$ Foi utilizada a variação do quantum para encadeamento da série das Contas Nacionais, que se iniciam em 1947.

Para a construção da série máquinas e equipamentos, foram utilizados como proxy os dados relativos à importação de bens de capital para a indústria, também de Villela e Suzigan (1973), uma vez que, no período considerado, 1901 a 1945, a indústria de bens de capital no Brasil ainda era incipiente, e a grande maioria da oferta desses bens era mediante a importação. ${ }^{4}$ Utilizou-se a variaçáo da série para encadear com a série disponível pelo IBGE de FBCF, que começa em 1947.

Para a elaboração da série outros, foi utilizado o índice de quantum de exportação de Villela e Suzigan (1973) e de Abreu (2014), pois a composição da FBCF no referido período (1901-1946) era basicamente de itens da lavoura permanente. Além disso, a produção doméstica de itens da lavoura permanente era na grande maioria destinada à exportação e composta basicamente por café, cana-de-açúcar, cacau, algodão e

3. Mesma metodologia usada por Morandi e Reis (2004).

4. Para 1946 foi utilizada a variação do quantum de importação geral obtida de Abreu (2014).

20 
borracha. 5 Sendo assim, a variação do índice de exportaçóes seria uma possível proxy para a variação da FBCF de outros. Foi construída, entáo, uma série a partir desses itens, pela qual foram extraídas as variaçóes para encadear a série disponível de FBCF do IBGE para os períodos anteriores a 1947.

\subsection{Desagregação da construção em residencial, infraestrutura e demais estruturas}

Ainda que a metodologia adotada neste texto busque utilizar as informaçóes mais desagregadas possíveis, com base nas estatísticas oficiais, a categoria construção não tem dados desagregados (exceto no SCN 2010). Devido à relevância da categoria e à necessidade de se ter dados com algum nível de desagregação, separaram-se inicialmente os totais obtidos para a construção em residencial e não residencial. Posteriormente, abriu-se o item não residencial em dois: infraestrutura e demais estruturas. Assim como na obtenção dos demais dados, a estratégia usada aqui foi a mesma: começar pelos dados da referência mais recente (SCN 2010), os quais apresentam maior desagregação e precisão, e encadear com os dados dos períodos anteriores. O deflacionamento dos dados náo foi alterado; adotou-se o mesmo deflator para os três subcomponentes da construção.

A participação do residencial e do não residencial na construção para o período 2010-2017 é obtida diretamente nos dados do SCN 2010. Para o período 2000-2009 encadeou-se o valor da FBCF residencial de 2010 por meio da taxa de crescimento da FBCF em construção realizada pelo setor institucional das famílias. Já a FBCF em construção não residencial é encontrada de forma residual, ao subtrair a residencial do total da construção. Para os períodos anteriores a 2000, utilizaram-se os dados das Estatísticas do Século XX, do IBGE. ${ }^{6}$ Com base nesses dados, calcula-se a participação da construção residencial e não residencial, aplicando-as sobre os totais já obtidos previamente. Com esse procedimento completa-se a série de 1901 a 1999.

Em posse da série de fluxo de investimento em construção não residencial para todo período de análise, é possível seguir para a segunda etapa: a separação entre infraestrutura e demais estruturas. Novamente, para o período de 2010-2017, existem

5. Mesma metodologia usada por Morandi e Reis (2004).

6. Disponível em: <https://seculoxx.ibge.gov.br/>. 
dados diretos sobre infraestrutura, sintetizados no produto obras de infraestrutura da TRU. Já o item demais estruturas é calculado de forma residual, descontando a infraestrutura do total de FBCF não residencial.

Para o subperíodo de 1996-2009, usou-se outra pesquisa do IBGE a fim de se obter a taxa de variação do fluxo de investimento em infraestrutura, a Pesquisa Anual da Indústria da Construção (PAIC), que apresenta informaçóes de acordo com a Classificação Nacional de Atividades Econômicas (CNAE). Foram escolhidas as atividades típicas da construção em infraestrutura e aplicado um tradutor (quadro B.3, no apêndice B). Pesquisas da PAIC compatíveis com a CNAE existem a partir de 1996, podendo então encadear os valores de 2010 para a infraestrutura da SCN 2010 até esse ano. Novamente, os valores para demais estruturas são calculados de forma residual.

Para o subperíodo 1947-1995, encadeou-se o valor das obras de infraestrutura com base nas taxas de variação da soma entre a FBCF do governo em construçáo e a FBCF das empresas estatais de setores ligados à infraestrutura (transportes, comunicação, energia e diversos) obtidas nas Estatísticas do Século XX. Como esse período antecede as privatizaçóes do setor, que começaram na segunda metade dos anos 1990, os investimentos feitos direta ou indiretamente pelo governo, por meio de empresas estatais, são uma boa proxy para os investimentos em infraestrutura lembrando que estamos utilizando apenas a taxa de variação para o encadeamento, não o nível.

Por fim, para 1901-1946, usou-se a participação da FBCF da administração pública na FBCF não residencial, também das Estatísticas do Século XX.

\subsection{Estimativa da depreciação}

Depois de realizados todos esses procedimentos, obtêm-se as séries de fluxos de investimento bruto a preços constantes para o período 1901-2017 aptas para a etapa de depreciação. O procedimento de depreciação da FBCF de 1970 a 2017 foi realizado produto a produto, com a taxa de depreciação e tempo de vida útil dos produtos extraídos do Bureau of Economic Analysis (BEA) dos Estados Unidos, conforme disponibilizado em OECD (2009) e BEA (2003). Nas tabelas B.1 a B.4 (apêndice B) podem ser encontradas as taxas de depreciação e tempo de vida útil de cada produto. 
Nessas mesmas tabelas também estão as correspondências adotadas entre o SCN (do IBGE) e as taxas de depreciação do BEA.

$\mathrm{Na}$ maioria dos casos, foram adotadas diretamente as medidas calculadas pelo BEA, exceto para alguns casos nos quais foram usadas outras fontes e/ou médias ponderadas de diversos itens. O caso notório é o das obras de infraestrutura, em que, devido à complexidade dos ativos e às grandes diferenças de composição em relaçáo aos Estados Unidos, utilizou-se a taxa de depreciaçáo estimada por Frischtak e Mouráo (2018) especificamente para o caso brasileiro. Os autores fizeram um levantamento detalhado de dados sobre a depreciação por setor (energia, telecomunicaçóes, saneamento e transportes) levando em consideração os dados de empresas e agências de regulação do Brasil e a composição desses setores no país. Obteve-se assim uma taxa de depreciação de 3,9\%, que é superior aos valores encontrados no BEA, que ficaram em torno de $2,5 \%$.

O uso de taxas de depreciação de produtos se restringiu à série com valores desagregados por produto. Para a depreciação dos investimentos feitos antes de 1970, foram adotadas as taxas médias de depreciação por componente. No caso, assumiu-se uma taxa média de depreciação e tempo de vida útil calculados com base nas informaçóes desagregadas por produto pós-1970: 12,73\% e 13 anos para outros; 12,44\% e 18 anos para máquinas e equipamentos; 2,93\% e 40 anos para a construção residencial; 3,9\% e 45 anos para a infraestrutura; e $2,48 \%$ e 38 anos para as demais estruturas.

\section{ESTIMATIVAS DAS SÉRIES ANUAIS: 1947-2017}

Esta seção traz uma síntese dos resultados obtidos. Os dados completos podem ser encontrados no apêndice $\mathrm{A}$, que mostra as tabelas com dados detalhados sobre as seguintes variáveis calculadas neste texto: FBCF a preços constantes; estoque líquido de capital fixo; investimento líquido; taxa de investimento; taxa de depreciação; e relação capital/produto.

O gráfico 5 mostra que, em termos agregados, a taxa de investimento (FBCF/PIB) se eleva no período 1969-1980. Com o colapso da economia brasileira na década de 1980, a taxa de investimento decaiu para um patamar inferior ao observado antes da 
década de 1970, mas alinhado à baixa taxa de poupança brasileira. O que se percebe a seguir é uma manutenção desse baixo nível de investimento, que somente apresentará sinais de recuperação após 2003, mas novamente não se mostrará sustentável e voltará a cair significativamente em 2014.

GRÁFICO 5

Taxa de investimento (1947-2017)

(FBCF em \% do PIB, a preços constantes de 2010)

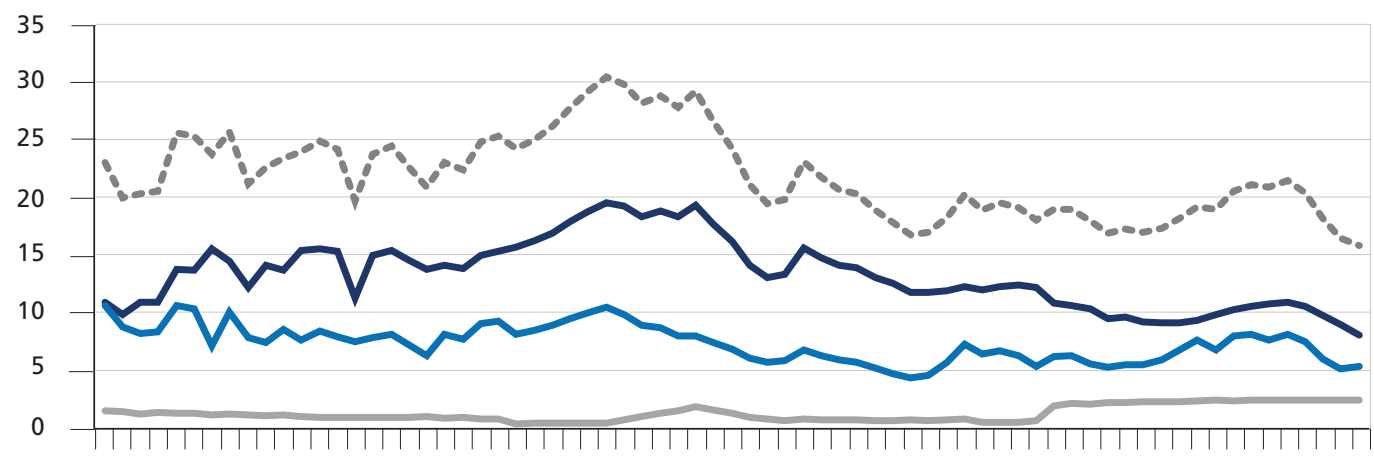

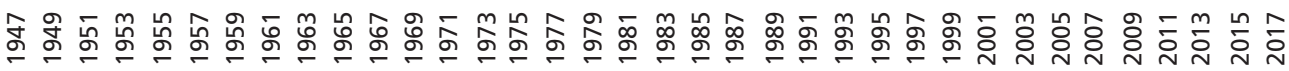

Construção Máquinas e equipamentos Outros @...Total

Elaboração dos autores.

Dado o elevado peso da construção, analisar a dinâmica de seus componentes pode trazer elementos importantes para explicar melhor a tendência da taxa de investimento. O gráfico 6 mostra que o investimento residencial é o principal componente da construção e dita boa parte de seu comportamento. As demais estruturas apresentam tendências semelhantes às do investimento residencial, ainda que com comportamentos cíclicos distintos. O componente que destoa dos demais é o investimento em infraestrutura, principalmente após meados da década de 1970, quando esse componente se torna significativamente menor que os demais. Somente a partir da metade da década de 1990 que a taxa de investimento em infraestrutura volta a crescer e retoma um papel mais significativo. 
Taxa de investimento: componentes da construção (1947-2017)

(Em \% do PIB, a preços constantes de 2010)

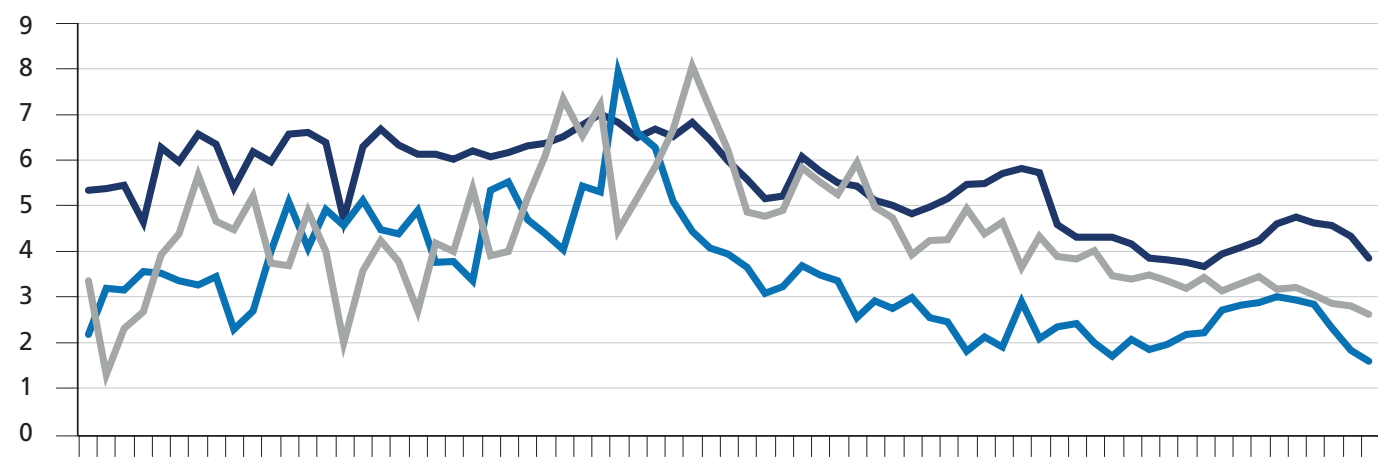

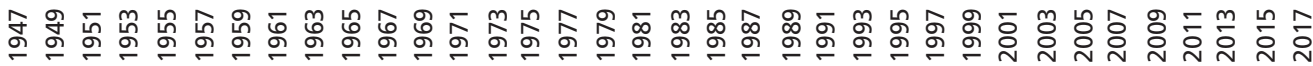

Elaboração dos autores.

O estoque de capital, como pode ser visto nos gráficos 7 e 8, apresenta crescimento em quase todo o período 1947-2017, exceto nos dois últimos anos da série. Em ambos os gráficos é possível visualizar o forte ritmo de acumulação de capital durante os anos 1960 e 1970, que só se reduz a partir da década de 1980. O período seguinte, compreendendo o intervalo de 1980 a 2005, foi marcado por grandes flutuaçóes no investimento líquido, mas com tendência de queda: em 1980, o investimento líquido (a preços constantes de 2010) era de R \$ 332 bilhóes, enquanto em 2003 era de R \$ 91 bilhôes. A partir de entáo houve um novo ciclo de expansão - com algumas quedas em anos específicos, como em 2009, muito por conta dos reflexos da crise de 2008 -, que se encerra apenas em 2013. Por fim, os anos de 2014 a 2017 apresentaram uma expressiva queda, semelhante à experiência ocorrida em 1981, 1982 e 1983. Com isso, em 2016 e 2017 ocorreu um fato, até então inédito, o investimento líquido foi negativo como mostra o gráfico 9. Em outras palavras, o investimento realizado não foi suficiente nem para repor o estoque de capital depreciado. 
GRÁFICO 7

Estoque de capital fixo (1947-2017)

(Em R\$ trilhões, a preços constantes de 2010)

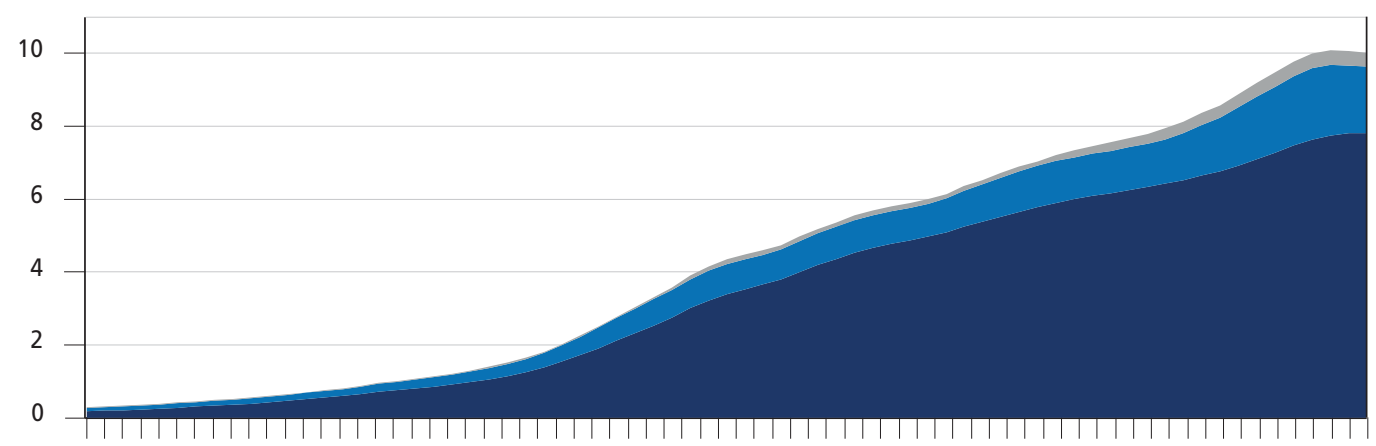

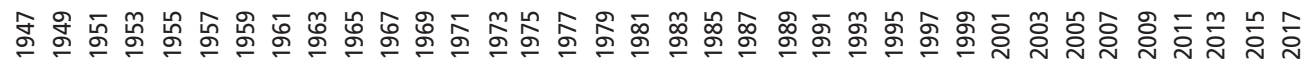

$$
\text { — Construção Máquinas e equipamentos }
$$

Elaboração dos autores.

GRÁFICO 8

Taxa de crescimento do estoque de capital (1947-2017)

(Em \% a.a.)

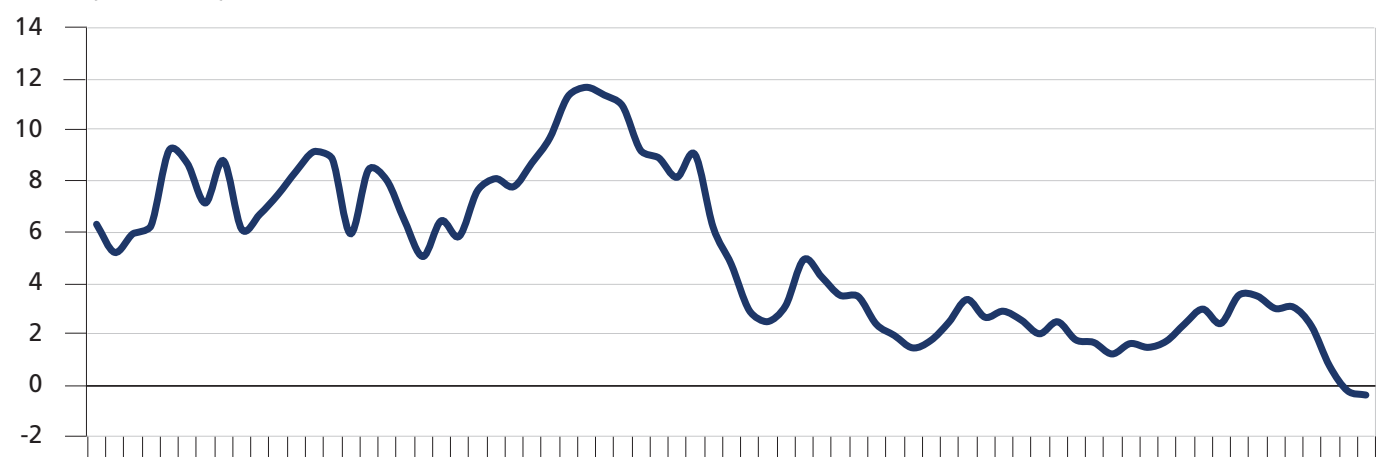

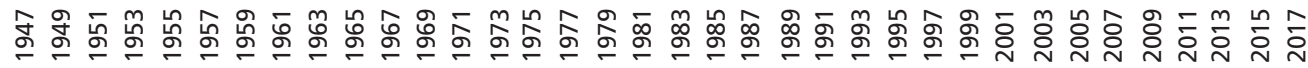
Elaboração dos autores. Obs.: a.a. - ao ano. 
GRÁFICO 9

Investimento líquido (1947-2017)

(Em R\$ bilhões, a preços constantes de 2010)

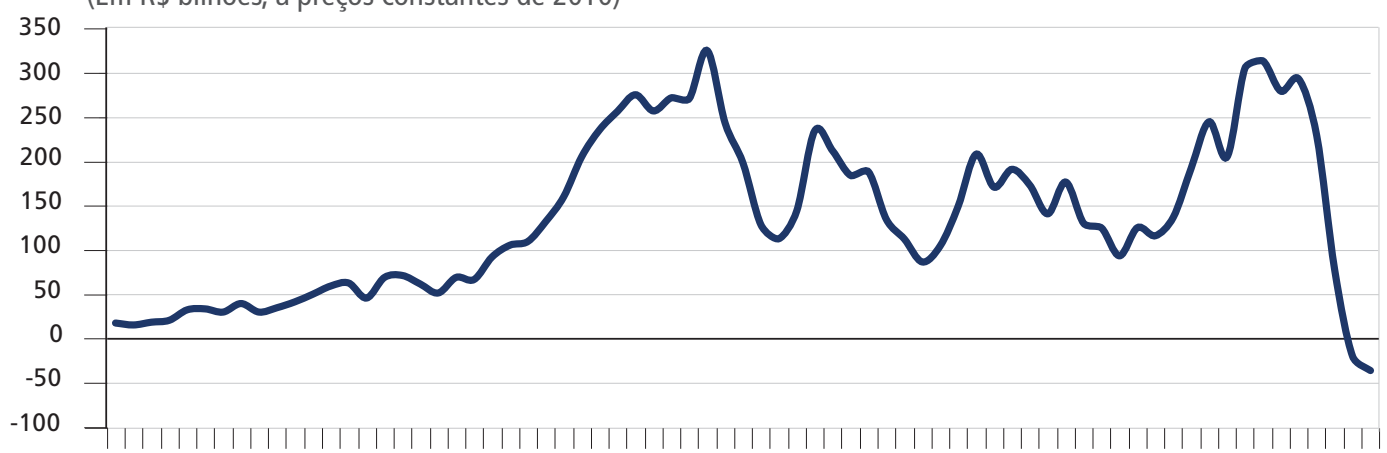

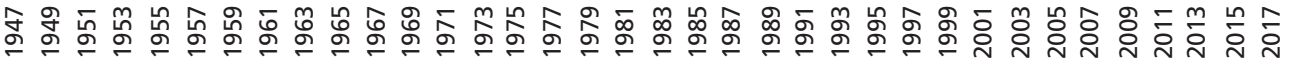
Elaboração dos autores.

No gráfico 10 é possível avaliar a composição do estoque de capital ao longo do período de análise. Em toda a série histórica, o item construção (soma de demais estruturas, infraestrutura e residencial) apresenta maior participação e um patamar amplamente maior que os demais. Isso decorre porque, além de apresentar um fluxo de investimento maior que os demais itens, tem taxa de depreciação menor e tempo de vida útil maior. Conforme esperado, a categoria residencial é a de maior peso no estoque de capital, devido ao seu maior fluxo de investimento, seguida da categoria demais estruturas. Já o item outros aumentou sua participação nos últimos anos devido à inclusão do componente pesquisa e desenvolvimento $(\mathrm{P} \& \mathrm{D})$ ao cálculo da FBCF.

GRÁFICO 10

Composição do estoque de capital (1947-2017)

(Em \%)

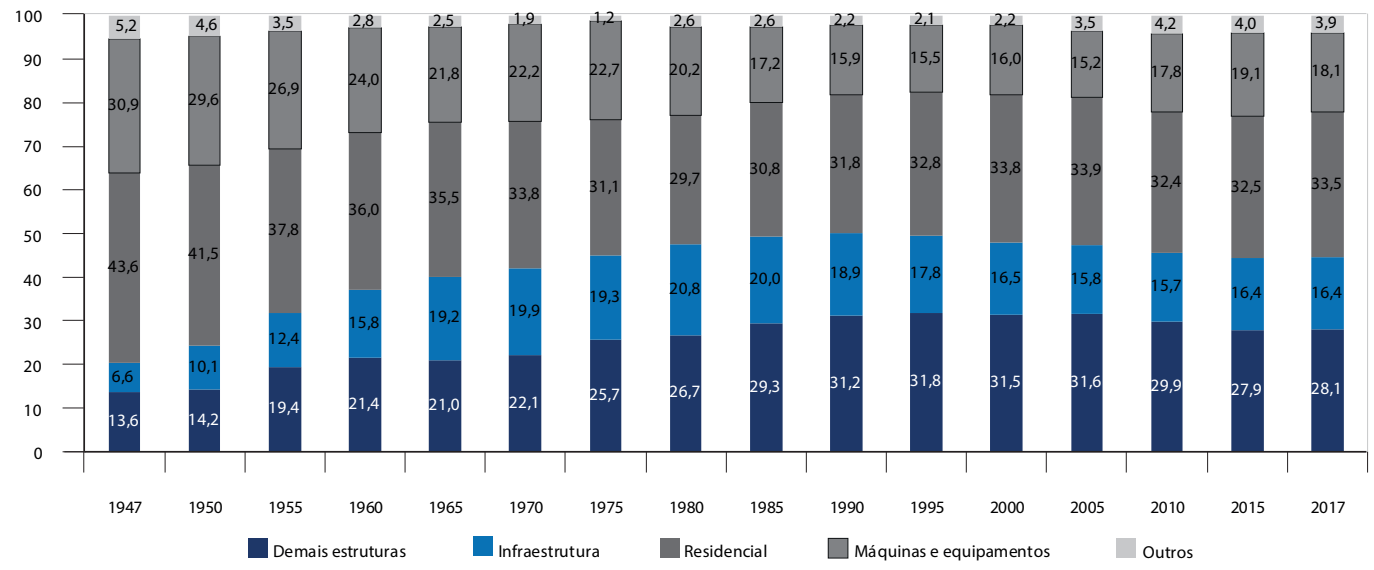

Elaboração dos autores. 
Essas flutuaçóes da composição do estoque, e mesmo a variação das participações de cada produto por componente, refletem-se no comportamento da taxa de depreciaçáo implícita agregada ${ }^{7}$ (gráfico 11). É possível perceber que, durante os períodos em que há redução da participação de construção, há um movimento de aumento da taxa de depreciação da economia como um todo. Esse movimento era esperado, especialmente pelo elevado peso desse item no estoque de capital total.

GRÁFICO 11

Taxa de depreciação implícita (1947-2017)

$(\mathrm{Em} \%)$

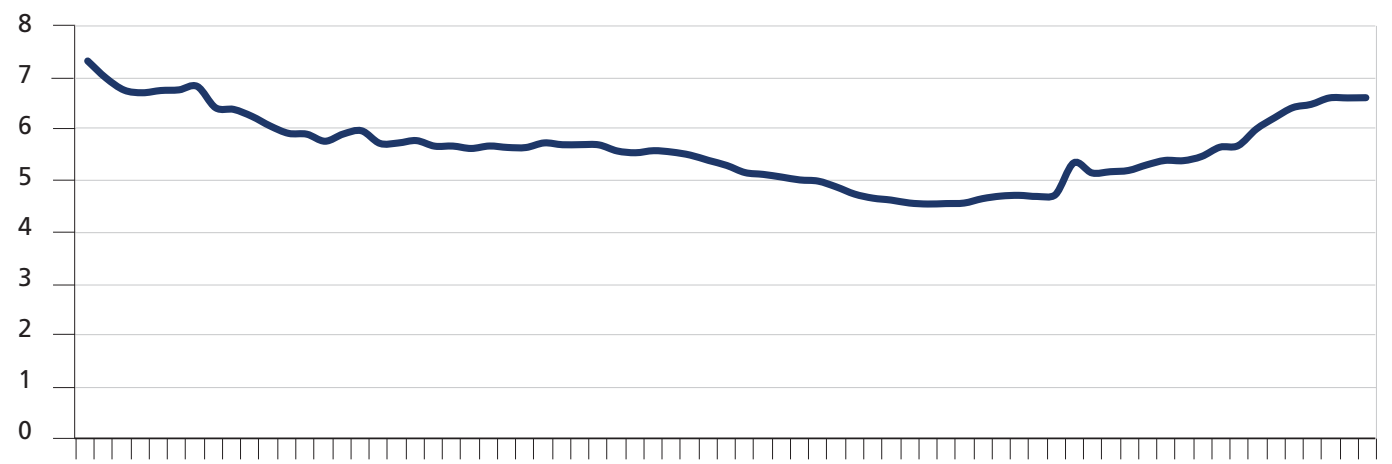

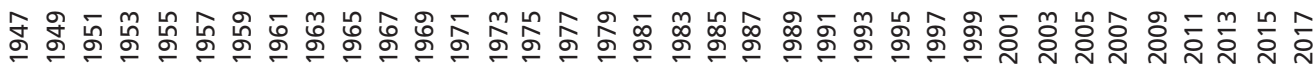

Elaboração dos autores.

Esses efeitos da composição do capital sobre a taxa média de depreciação podem ser mais bem avaliados com base na desagregação por subperíodos selecionados da tabela 1 e na decomposição da taxa de depreciação por categoria e subperíodo da tabela 2. Outra importante informação que pode ser extraída da tabela 2 é que a própria taxa de depreciação por categoria também é afetada por alterações na composição por produto de cada categoria, pois cada produto apresenta uma taxa de depreciaçáo e tempo de vida útil específico. A mudança mais significativa ocorre no item outros após a revisão metodológica realizada na SCN 2010 com a entrada de P\&D como item da FBCF - que tem taxa de depreciação elevada.

7. 0 cálculo da taxa de depreciação agregada implícita decorre da própria definição do estoque de capital encontrada na equação (4), que, após realizar algumas manipulações algébricas, pode ser convertida em:

$\delta=I_{b, t}-I_{l, t} / K_{t-1}=I_{r, t} / K_{t-1}$ 
2580 Estoque de Capital Fixo no Brasil: séries desagregadas anuais, trimestrais e mensais

TABELA 1

Composição média do estoque de capital em períodos selecionados

(Em \% do estoque de capital total)

\begin{tabular}{|c|c|c|c|c|c|c|c|}
\hline \multirow{2}{*}{ Categorias } & \multicolumn{7}{|c|}{ Composição média do estoque de capital } \\
\hline & 1947-1959 & 1960-1969 & 1970-1979 & 1980-1989 & 1990-1999 & $2000-2009$ & 2010-2017 \\
\hline Residencial & 39,48 & 35,24 & 31,64 & 30,61 & 32,81 & 33,63 & 32,49 \\
\hline Infraestrutura & 11,34 & 18,20 & 20,23 & 19,99 & 17,95 & 15,97 & 16,15 \\
\hline Demais estruturas & 17,27 & 21,33 & 24,40 & 29,00 & 31,68 & 31,33 & 28,52 \\
\hline Máquinas e equipamentos & 27,93 & 22,69 & 22,15 & 17,81 & 15,56 & 15,77 & 18,76 \\
\hline Outros & 3,98 & 2,54 & 1,59 & 2,58 & 2,00 & 3,31 & 4,09 \\
\hline Total & 100,00 & 100,00 & 100,00 & 100,00 & 100,00 & 100,00 & 100,00 \\
\hline
\end{tabular}

Elaboração dos autores.

TABELA 2

Taxa de depreciação implícita: média por categoria e subperíodo (Em \%)

\begin{tabular}{|c|c|c|c|c|c|c|c|}
\hline \multirow{2}{*}{ Categorias } & \multicolumn{7}{|c|}{ Subperíodo } \\
\hline & 1947-1959 & $1960-1969$ & 1970-1979 & $1980-1989$ & 1990-1999 & $2000-2009$ & $2010-2017$ \\
\hline Residencial & 3,26 & 3,19 & 3,12 & 3,07 & 3,10 & 3,23 & 3,61 \\
\hline Infraestrutura & 4,81 & 4,43 & 4,42 & 4,16 & 4,07 & 4,13 & 4,24 \\
\hline Demais estruturas & 2,37 & 2,42 & 2,18 & 2,42 & 2,71 & 2,91 & 3,66 \\
\hline Máquinas e equipamentos & 13,25 & 13,08 & 13,73 & 13,13 & 11,64 & 13,25 & 13,45 \\
\hline Outros & 15,00 & 14,65 & 13,98 & 11,44 & 11,91 & 18,77 & 23,85 \\
\hline Total & 6,61 & 5,81 & 5,69 & 5,16 & 4,67 & 5,32 & 6,39 \\
\hline
\end{tabular}

Por fim, uma informação relevante para estudos de crescimento e distribuição é a relação capital/produto (gráfico 12). É preciso analisar esses dados com cuidado, pois suas variaçóes são resultado tanto de variaçóes no ritmo de acumulaçáo quanto da dinâmica de crescimento do PIB. Na série em questão, o exemplo mais notório é o grande aumento da relação capital/produto no período 1973-1983, que também pode ser desmembrado em dois períodos com dinâmicas distintas. De 1973 a 1979, período de intensa industrialização e forte incentivo público ao investimento, o aumento da relação capital/produto foi decorrente do crescimento acelerado do numerador (estoque de capital), relativamente maior que do denominador (PIB). Já no período subsequente, a variação dominante foi o baixo crescimento do PIB (com períodos de recessão), que reduz relativamente o denominador. 


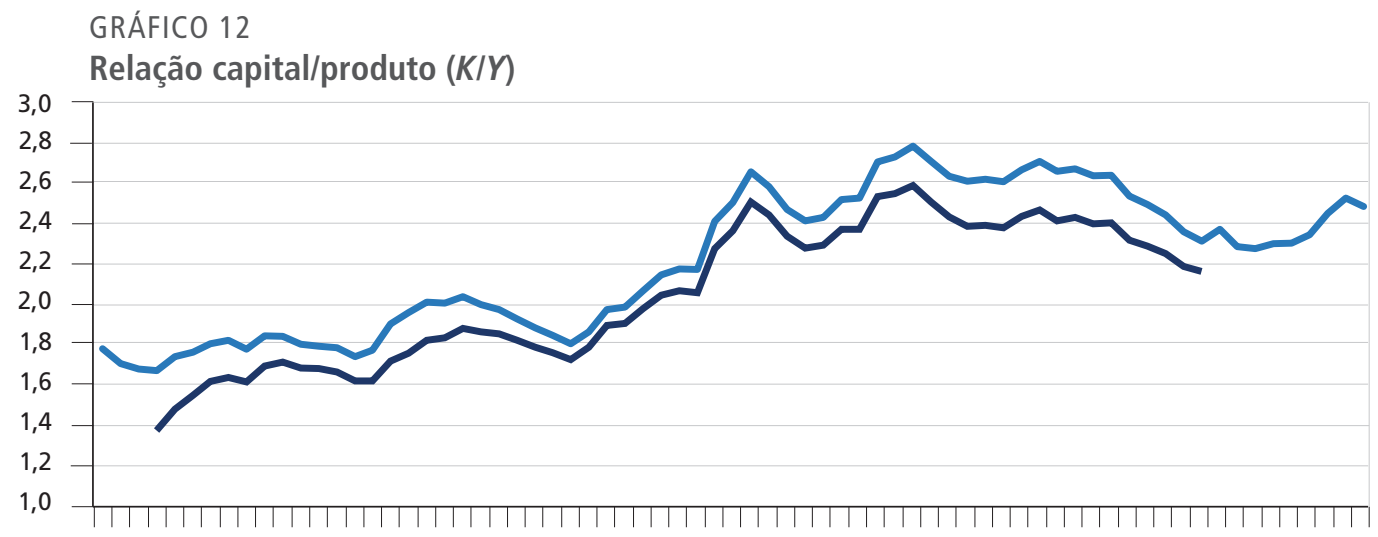

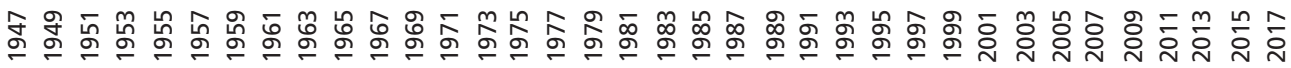
Morandi e Reis (2004) Nossos cálculos

Elaboração dos autores.

Obs.: A série da metodologia de Morandi e Reis (2004) foi atualizada pelo Ipeadata para o período até 2008.

No gráfico 12 é possível comparar os resultados obtidos com os encontrados em Morandi e Reis (2004) para a relação capital/produto. Há uma evidente diferença no nível da série, com a nossa estimativa ficando com valores acima do antes obtido ao longo de todo período, mas que a princípio parecem ter um comportamento semelhante. Se examinarmos apenas a diferença entre as séries (gráfico 13), percebe-se, no entanto, que as diferenças não são constantes. As diferenças entre as metodologias não ficaram apenas no período em que há a desagregação (1970 em diante) mas também em períodos anteriores. Isso decorre da mudança nos valores da taxa de depreciação e tempo de vida útil das categorias, calculadas a partir de uma média ponderada do período em que há desagregação. 


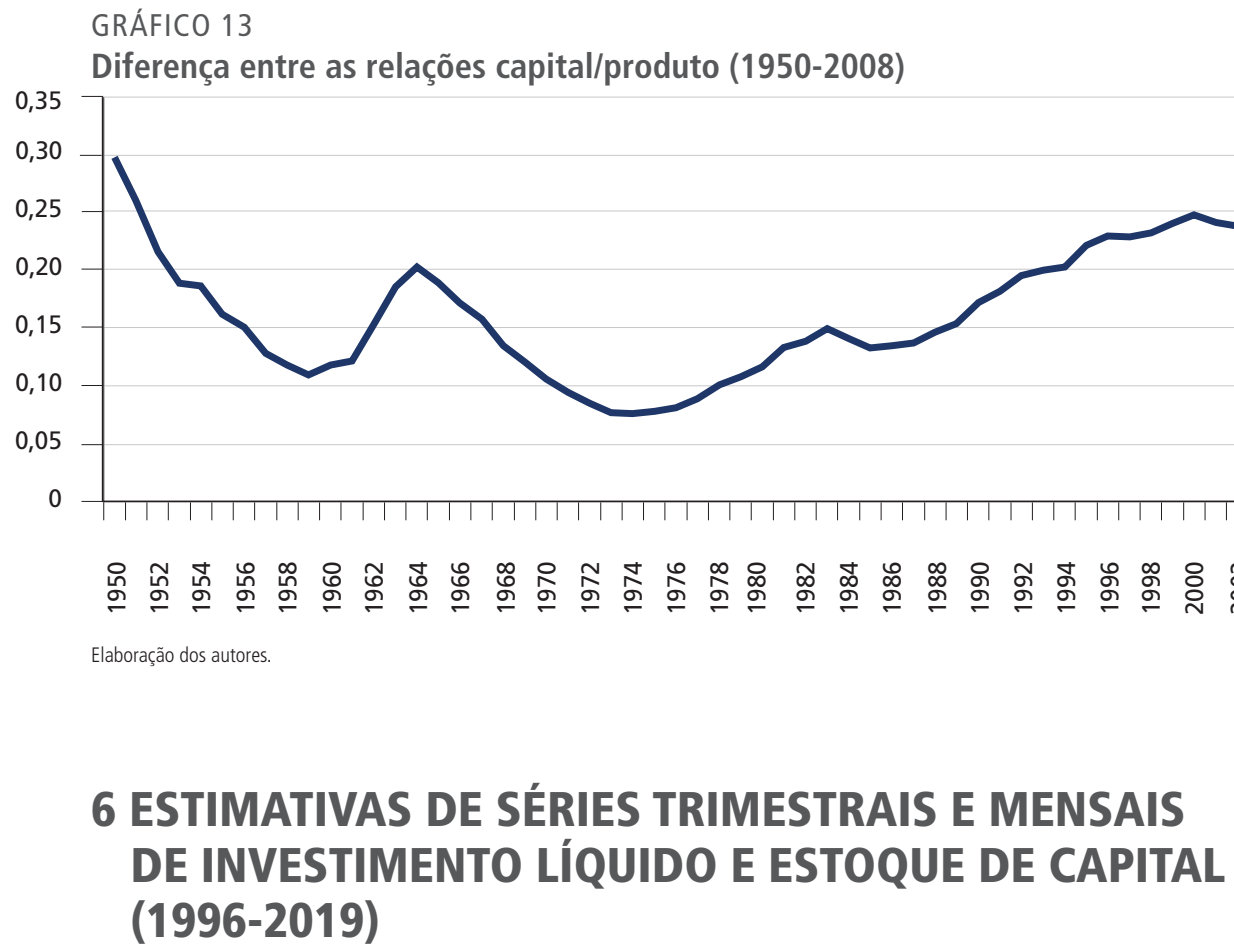

A desagregação temporal e a maior contemporaneidade das atualizaçóes da série de estoque de capital são fundamentais para a sua utilizaçáo no debate macroeconômico conjuntural, tanto em relação à dinâmica do investimento como no que se refere às estimativas de produto potencial por meio da função de produção. Os dados aqui estimados serão apresentados na versão com maior frequência (no caso, a mensal). Conforme pode ser visto na fonte dos dados mensais do Ipea (Carvalho e Ribeiro, 2017), a aplicação do método de desagregação temporal garante que as variaçôes mensais da FBCF em um trimestre sejam exatamente os mesmos valores trimestrais do SCNT (do IBGE) - consequentemente também compatíveis com as séries anuais.

Ainda que a estimaçáo anual seja realizada em relação a produto, os resultados finais podem ser agregados nas três categorias da FBCF, a saber: máquinas e equipamentos, construção e outros - mesma desagregação que é disponibilizada mensalmente pelos dados de fluxo do Ipea. Os dados das contas nacionais anuais, mesmo na metodologia mais recente (SCN 2010), ainda apresentam uma defasagem de cerca de dois anos se comparada às séries trimestrais do IBGE (SCNT) e aos dados mensais do Ipea. Já em relação à depreciação do estoque de capital, a partir das informaçôes anuais, é possível 
somente estimar no máximo a depreciação de um período à frente de forma direta - com base nos dados desagregados por produto de estoque do ano anterior. A fim de se estimar preliminarmente o estoque de capital para um segundo ano à frente, a depreciaçáo incide sobre o estoque já adicionado das informaçôes trimestrais/mensais com um nível de agregação maior, por categoria.

Em posse das séries anuais de estoque de capital e de investimento líquido é possível desagregá-las temporalmente ao longo do ano com base no fluxo de investimento gerado durante o ano. Com base na série de FBCF mensal do Ipea - que é compatível com as séries trimestrais do IBGE -, estimamos o investimento líquido mensalmente, de forma que a sua soma no ano seja o investimento líquido obtido na série anual, ${ }^{8}$ estimado pelo método de Denton (1971). Ou seja, em dezembro de cada ano, teremos exatamente os valores do estoque de capital obtidos na série anual.

A metodologia citada somente é aplicada para o período em que há informaçôes anuais, necessitando de adaptaçóes para os períodos posteriores. Como os dados mensais só estão disponíveis por categoria, não podendo ser aplicada a metodologia de deflacionamento e depreciação em relação aos produtos, encadeamos os dados de fluxo de investimentos brutos mensais de cada categoria. A obtenção da depreciação, por sua vez, ocorre de forma distinta.

Para o ano subsequente ao último dado anual disponível, aplicam-se as taxas de depreciação em relação ao produto sobre o estoque de capital passado. Para o ano subsequente, contudo, a FBCF mais agregada já conta na depreciação, tendo dois estoques a serem depreciados de forma distinta.

O estoque remanescente da série anual continuará a ser depreciado a partir das taxas em relação ao produto, enquanto o novo fluxo de investimento ao nível das três categorias será depreciado a partir da taxa de depreciação implícita de sua categoria, obtida no ano anterior, que tende a refletir uma composição de estoque de capital semelhante a que seria depreciada.

8. Nessa metodologia, a depreciação mensal do estoque de capital é distribuída de forma proporcional ao investimento bruto, tendo em vista que a desagregação temporal é aplicada após a extração da depreciação do estoque de capital do ano anterior, distribuindo ao longo do ano o investimento já líquido. 
O gráfico 14 mostra os dados do investimento líquido mensal acumulado em doze meses para o período de dezembro de 1996 a dezembro de 2019. A partir de 2016, os investimentos brutos não foram suficientes sequer para repor a depreciação do capital instalado na economia - como visto anteriormente na série anual até 2017. $\mathrm{O}$ resultado foi que o estoque de capital apresentou inéditas taxas negativas de variação, como mostra o gráfico 15. Apenas ao final de 2019, o investimento líquido convergiu para um valor próximo de zero, e, por conseguinte, o estoque de capital passou a ficar próximo à estabilidade.

Por último, é bom lembrar que esses dados de 2018 e 2019 são preliminares e devem ser revistos quando forem divulgados os dados anuais completos - mais precisos e desagregados por produto.

GRÁFICO 14

Investimento líquido mensal (dez./1996-dez./2019)

(Acumulado em 12 meses, em R\$ bilhões de 2010)
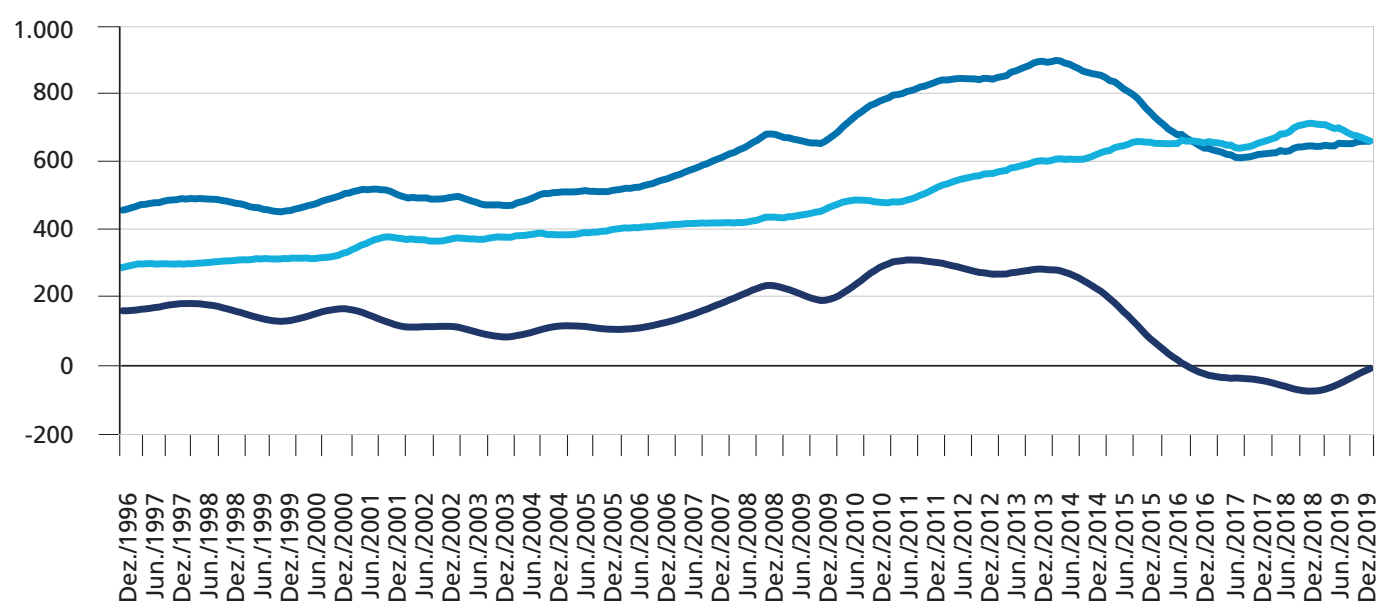

Investimento líquido

Investimento bruto

Investimento em reposição de depreciação 
GRÁFICO 15

Estoque de capital: taxa de crescimento mensal (jan./1997-dez./2019)

(Em \%)

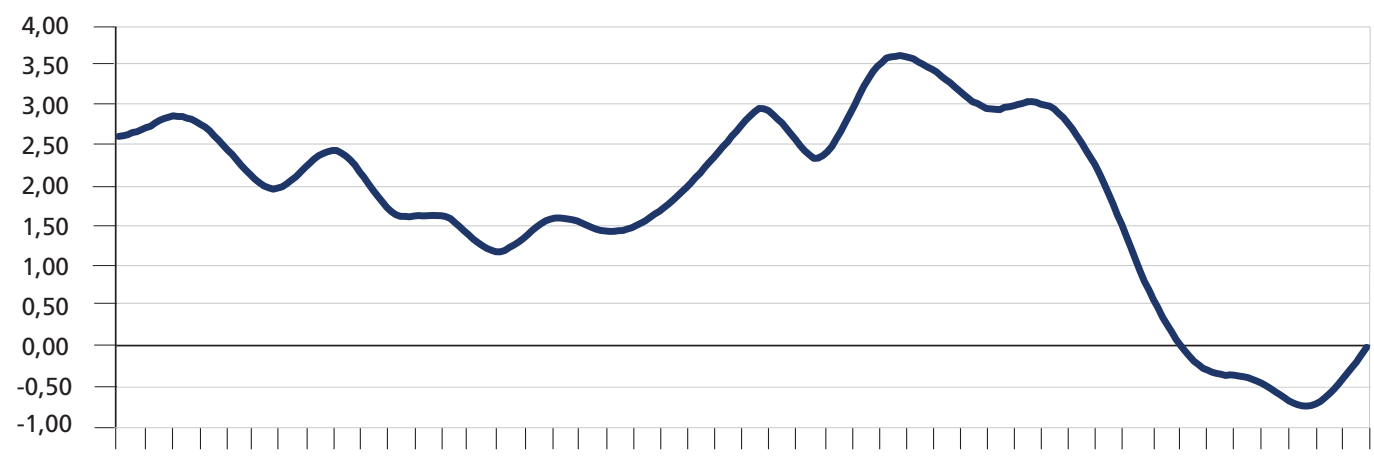

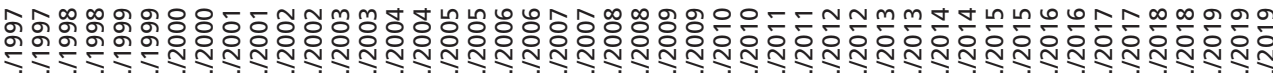

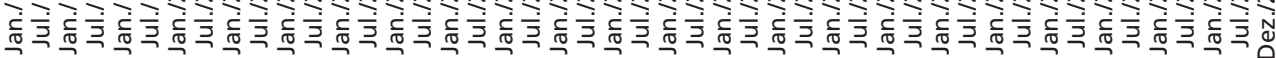

Elaboração dos autores.

\section{CONSIDERAÇÕES FINAIS}

Um extenso levantamento e tratamento de dados históricos foi necessário para a obtenção de séries desagregadas com o maior nível de detalhamento possível por safras de investimentos. Ainda assim, os dados mais recentes de investimentos, especialmente aqueles a partir de 2010, são mais precisos e detalhados que os mais antigos. Dados desagregados por produtos e compatíveis entre si estão disponíveis a partir de 1970, mesmo que sofrendo com mudanças metodológicas durante alguns períodos. As séries estimadas para os anos anteriores a 1947 foram utilizadas apenas para se obter um estoque de capital completo a partir desse ano, ou seja, com a depreciação total do primeiro fluxo de investimento.

Os resultados obtidos se mostraram aderentes ao desempenho histórico da economia brasileira. Até 1973, a relação capital/produto ficava em torno de 1,7 e 2, porém cresceu sistematicamente a partir de 1974 e atingiu um pico de 2,7 em 1984. Manteve-se em torno desse patamar até que, nos anos 2000, caiu a 2,3 no final da década. Com a recessão iniciada em meados de 2014, essa relação subiu novamente para 2,5 nos anos subsequentes.

34 
A relação capital/produto costuma ter um comportamento anticíclico dado que é medido por meio de uma relaçáo entre o estoque de capital corrente e o produto corrente. É necessário cuidado ao avaliar essa informação, visto que um aumento na relação capital/produto pode refletir tanto um ritmo de acumulaçáo acelerado quanto um período de forte recessão.

Outro destaque é que, mesmo em períodos de sucessivos anos de queda dos investimentos brutos, o investimento líquido durante quase toda a série estimada foi positivo e, portanto, houve crescimento do estoque de capital. A exceção é o período de 2016 a 2018, quando a taxa de investimento chegou a níveis tão baixos que a FBCF sequer foi capaz de repor as perdas com depreciação.

A composição do estoque de capital foi ditada basicamente por um aumento da participação de máquinas e equipamentos - em detrimento da participação da construção -, quando ocorreram os esforços de industrialização liderados pelo governo. Isso se refletiu inclusive no comportamento da taxa de depreciação, que tende a acelerar quando a construção perde peso no estoque de capital. Esse comportamento da taxa de depreciação agregada é decorrente da taxa de depreciação mais baixa e do maior tempo de vida útil dos produtos que compóem a categoria construção. No outro extremo, há ampliação da taxa de depreciação agregada na medida em que aumenta a participação da categoria máquinas e equipamentos e, principalmente, da categoria outros.

Algumas lacunas, como a baixa frequência dos dados (série anual) e a falta de estimativa para os anos mais recentes (2018 e 2019), foram resolvidas ao desagregar temporalmente as informaçóes trimestrais da FBCF no SCNT e do indicador Ipea mensal de FBCF. Com isso, obtiveram-se medidas mensais de estoque de capital e investimento líquido para o período 1996-2019. Ainda que o comportamento tendencial das séries seja o mesmo da série anual, os dados de frequência mais alta trazem informaçóes relevantes para se entender movimentos conjunturais e cíclicos da economia.

Por fim, a criação dessa metodologia é um primeiro passo para a elaboração de estimativas para o estoque de capital em nível de produtos e setores. Para isso ser possível, é necessária uma série desagregada mais longa, para se ter ao menos um ciclo de depreciação de cada produto. 


\section{REFERÊNCIAS}

ABREU, M. P. (Org.). A ordem do progresso: dois séculos de política econômica no Brasil. 2 ed. Rio de Janeiro: Elsevier, 2014.

CARVALHO, L. M. de; RIBEIRO, F. J. da S. P. Metodologia de cálculo do indicador Ipea mensal de Formaçáo Bruta de Capital Fixo. Rio de Janeiro: Ipea, 2017. (Carta de Conjuntura, n. 37).

DENTON, F. T. Adjustment of monthly or quarterly series to annual totals: an approach based on quadratic minimization. Journal of the American Statistical Association, v. 66, n. 333, p. 99-102, 1971.

EUROPEAN COMMISSION et al. System of National Accounts: 1993. New York: UN, 1993. System of National Accounts: 2008. New York: UN, 2009.

FEIJÓ, C. A.; RAMOS, R. L. O. (Org.). Contabilidade social: a nova referência das Contas Nacionais do Brasil. Rio de Janeiro: Elsevier, 2013.

FRISCHTAK, C. R.; MOURÁO, J. Uma estimativa do estoque de capital de infraestrutura no Brasil. In: DE NEGRI, J. A.; ARAÚJO, B. C.; BACELETTE, R. (Org.). Desafios da naçáo: artigos de apoio. Brasília: Ipea, 2018. v. 1.

HALLAK NETO, J.; FORTE, C. M. O Sistema de Contas Nacionais: evoluçáo histórica e implantação no Brasil. Revista Econômica, v. 18, n. 1, p. 1-27, 2016.

HOFMAN, A. A. Capital accumulation in Latin America: a six-country comparison for 1950-89. Review of Income and Wealth, v. 38, n. 4, p. 365-401, 1992.

. Standardised capital stock estimates in Latin America: a 1950-94 update. Cambridge Journal of Economics, v. 24, n. 1, p. 45-86, 2000.

MARQUETTI, A. Estimativa do estoque de riqueza tangível no Brasil, 1950-1998. Nova Economia, v. 10, n. 2, p. 11-37, 2000.

MENEZES, A. C.; ORTEGA, J. A. Matrizes insumo-produto brasileiras 1970, 1975 e 1980: compatibilização de atividades e produtos - metodologia e resultados. Rio de Janeiro: Editora UFRJ, 1991. 72 p.

MORANDI, L. Estimativas de estoque de capital fixo com as novas contas nacionais, Brasil: 1940-2009. Niterói: Eduff, 2011. (Texto para Discussão, n. 276).

MORANDI, L.; REIS, E. J. Estoque de capital fixo no Brasil, 1950-2002. In: ENCONTRO NACIONAL DE ECONOMIA, 32., 2011, João Pessoa, Paraíba. Anais... João Pessoa: Anpec, 2004. 
OECD - ORGANISATION FOR ECONOMIC CO-OPERATION AND DEVELOPMENT. Measuring capital: OECD manual. 2. ed. Paris: OECD, 2009.

UN - UNITED NATIONS. A System of National Accounts. New York: UN, 1968.

VILLELA, A. V.; SUZIGAN, W. Política do governo e crescimento da economia brasileira, 1889-1945. Rio de Janeiro: Ipea, 1973. 


\section{APÊNDICE A}

TABELA A.1

Formação Bruta de Capital Fixo (FBCF): valores constantes de 2010 (1947-2017)

(Em R\$ milhões)

\begin{tabular}{|c|c|c|c|c|c|c|c|}
\hline & \multicolumn{4}{|c|}{ Construção } & \multirow{3}{*}{ Máquinas e equipamentos } & \multirow{3}{*}{ Outros } & \multirow{3}{*}{ Total } \\
\hline & \multirow{2}{*}{ Residencial } & \multicolumn{2}{|c|}{ Não residencial } & \multirow{2}{*}{ Total } & & & \\
\hline & & Infraestrutura & Demais estruturas & & & & \\
\hline 1947 & 8.952 & 3.664 & 5.640 & 18.256 & 17.835 & 2.506 & 38.597 \\
\hline 1948 & 9.890 & 5.859 & 2.383 & 18.132 & 16.073 & 2.544 & 36.749 \\
\hline 1949 & 10.814 & 6.239 & 4.564 & 21.618 & 16.167 & 2.431 & 40.216 \\
\hline 1950 & 9.812 & 7.547 & 5.657 & 23.016 & 17.587 & 2.884 & 43.487 \\
\hline 1951 & 13.960 & 7.806 & 8.738 & 30.504 & 23.587 & 2.783 & 56.874 \\
\hline 1952 & 14.200 & 8.011 & 10.442 & 32.653 & 24.585 & 2.978 & 60.216 \\
\hline 1953 & 16.407 & 8.165 & 14.146 & 38.718 & 17.672 & 2.825 & 59.215 \\
\hline 1954 & 17.096 & 9.289 & 12.531 & 38.916 & 26.990 & 3.124 & 69.029 \\
\hline 1955 & 15.780 & 6.688 & 13.104 & 35.572 & 22.960 & 3.275 & 61.807 \\
\hline 1956 & 18.641 & 8.143 & 15.714 & 42.499 & 22.186 & 3.243 & 67.928 \\
\hline 1957 & 19.325 & 12.952 & 12.142 & 44.419 & 27.724 & 3.596 & 75.739 \\
\hline 1958 & 23.647 & 18.253 & 13.264 & 55.163 & 27.302 & 3.555 & 86.020 \\
\hline 1959 & 26.064 & 16.062 & 19.253 & 61.380 & 33.119 & 3.706 & 98.204 \\
\hline 1960 & 27.608 & 21.242 & 17.274 & 66.124 & 34.172 & 3.908 & 104.205 \\
\hline 1961 & 22.001 & 21.420 & 9.382 & 52.803 & 35.038 & 4.155 & 91.996 \\
\hline 1962 & 31.469 & 25.550 & 17.874 & 74.893 & 39.208 & 4.419 & 118.520 \\
\hline 1963 & 33.578 & 22.524 & 21.298 & 77.400 & 40.644 & 4.690 & 122.734 \\
\hline 1964 & 32.901 & 22.774 & 19.686 & 75.362 & 37.330 & 4.560 & 117.252 \\
\hline 1965 & 32.620 & 26.057 & 14.338 & 73.015 & 33.112 & 5.118 & 111.244 \\
\hline 1966 & 34.792 & 21.352 & 23.764 & 79.909 & 46.022 & 4.765 & 130.696 \\
\hline 1967 & 35.583 & 22.368 & 23.705 & 81.656 & 45.458 & 5.175 & 132.289 \\
\hline 1968 & 40.281 & 21.809 & 34.951 & 97.040 & 58.758 & 5.180 & 160.978 \\
\hline 1969 & 43.271 & 38.046 & 27.816 & 109.133 & 65.844 & 5.216 & 180.193 \\
\hline 1970 & 48.393 & 43.458 & 31.462 & 123.313 & 63.840 & 2.893 & 190.046 \\
\hline 1971 & 55.301 & 41.086 & 45.313 & 141.699 & 73.892 & 3.302 & 218.893 \\
\hline 1972 & 62.421 & 43.013 & 59.829 & 165.263 & 86.805 & 3.824 & 255.893 \\
\hline 1973 & 72.647 & 44.942 & 81.900 & 199.488 & 105.540 & 4.584 & 309.612 \\
\hline 1974 & 81.688 & 65.592 & 78.971 & 226.251 & 120.563 & 5.162 & 351.977 \\
\hline 1975 & 88.902 & 67.340 & 91.478 & 247.720 & 132.954 & 5.612 & 386.286 \\
\hline 1976 & 95.560 & 111.057 & 62.435 & 269.052 & 137.596 & 10.174 & 416.822 \\
\hline 1977 & 95.353 & 97.140 & 75.887 & 268.380 & 130.551 & 14.165 & 413.096 \\
\hline 1978 & 102.885 & 96.801 & 90.334 & 290.021 & 133.928 & 19.591 & 443.540 \\
\hline
\end{tabular}


Texto para

Discussão

Estoque de Capital Fixo no Brasil: séries desagregadas anuais, trimestrais e mensais

\begin{tabular}{|c|c|c|c|c|c|c|c|}
\hline & \multicolumn{4}{|c|}{ Construção } & \multirow{3}{*}{ Máquinas e equipamentos } & \multirow{3}{*}{ Outros } & \multirow{3}{*}{ Total } \\
\hline & \multirow{2}{*}{ Residencial } & \multicolumn{2}{|c|}{ Não residencial } & \multirow{2}{*}{ Total } & & & \\
\hline & & Infraestrutura & Demais estruturas & & & & \\
\hline 1979 & 107.127 & 84.015 & 109.610 & 300.752 & 131.564 & 24.702 & 457.018 \\
\hline 1980 & 122.745 & 79.648 & 144.906 & 347.299 & 143.581 & 33.526 & 524.406 \\
\hline 1981 & 110.718 & 70.205 & 122.448 & 303.370 & 126.990 & 26.250 & 456.611 \\
\hline 1982 & 103.824 & 68.416 & 107.977 & 280.217 & 118.739 & 21.461 & 420.416 \\
\hline 1983 & 93.911 & 61.631 & 81.976 & 237.518 & 101.860 & 15.844 & 355.223 \\
\hline 1984 & 91.622 & 54.846 & 84.704 & 231.171 & 100.312 & 13.151 & 344.634 \\
\hline 1985 & 99.900 & 61.683 & 93.901 & 255.484 & 112.151 & 12.043 & 379.677 \\
\hline 1986 & 125.188 & 75.776 & 120.030 & 320.995 & 138.411 & 15.301 & 474.706 \\
\hline 1987 & 122.627 & 74.220 & 117.581 & 314.428 & 133.157 & 15.152 & 462.737 \\
\hline 1988 & 117.115 & 71.443 & 111.737 & 300.295 & 124.880 & 14.627 & 439.803 \\
\hline 1989 & 119.152 & 55.903 & 130.462 & 305.517 & 124.743 & 15.039 & 445.299 \\
\hline 1990 & 107.446 & 61.246 & 104.311 & 273.003 & 109.424 & 13.577 & 396.004 \\
\hline 1991 & 106.413 & 58.520 & 100.524 & 265.457 & 99.009 & 13.729 & 378.195 \\
\hline 1992 & 101.812 & 62.994 & 82.988 & 247.794 & 92.096 & 14.309 & 354.199 \\
\hline 1993 & 109.903 & 56.337 & 93.839 & 260.079 & 100.610 & 14.516 & 375.204 \\
\hline 1994 & 120.183 & 57.085 & 99.041 & 276.309 & 132.739 & 16.209 & 425.257 \\
\hline 1995 & 132.805 & 44.265 & 120.028 & 297.099 & 176.247 & 18.198 & 491.544 \\
\hline 1996 & 136.454 & 52.782 & 108.889 & 298.125 & 159.049 & 12.326 & 469.500 \\
\hline 1997 & 146.997 & 48.900 & 119.517 & 315.415 & 172.529 & 12.974 & 500.917 \\
\hline 1998 & 150.197 & 74.627 & 94.066 & 318.890 & 161.473 & 12.719 & 493.082 \\
\hline 1999 & 148.667 & 53.928 & 112.311 & 314.906 & 137.351 & 15.262 & 467.520 \\
\hline 2000 & 124.188 & 63.280 & 105.037 & 292.505 & 167.802 & 52.268 & 512.574 \\
\hline 2001 & 118.443 & 66.466 & 105.162 & 290.071 & 171.235 & 58.142 & 519.447 \\
\hline 2002 & 122.055 & 56.616 & 113.512 & 292.182 & 156.837 & 57.718 & 506.738 \\
\hline 2003 & 123.225 & 48.489 & 98.874 & 270.589 & 149.491 & 63.506 & 483.586 \\
\hline 2004 & 125.796 & 62.513 & 102.767 & 291.077 & 165.383 & 65.699 & 522.158 \\
\hline 2005 & 120.212 & 57.780 & 109.027 & 287.019 & 171.267 & 69.776 & 528.062 \\
\hline 2006 & 123.668 & 63.559 & 109.002 & 296.229 & 192.480 & 73.210 & 561.919 \\
\hline 2007 & 129.551 & 74.807 & 109.800 & 314.159 & 232.364 & 78.101 & 624.623 \\
\hline 2008 & 132.375 & 80.035 & 124.363 & 336.773 & 274.175 & 83.122 & 694.070 \\
\hline 2009 & 142.433 & 98.080 & 113.189 & 353.701 & 243.418 & 86.161 & 683.281 \\
\hline 2010 & 159.167 & 109.773 & 128.370 & 397.310 & 310.656 & 89.980 & 797.946 \\
\hline 2011 & 171.005 & 115.980 & 139.499 & 426.485 & 328.266 & 97.727 & 852.478 \\
\hline 2012 & 189.409 & 123.769 & 130.457 & 443.635 & 314.330 & 99.973 & 857.937 \\
\hline 2013 & 201.595 & 124.578 & 135.964 & 462.136 & 344.003 & 101.953 & 908.092 \\
\hline 2014 & 196.781 & 121.044 & 129.650 & 447.475 & 319.363 & 102.590 & 869.428 \\
\hline 2015 & 187.913 & 95.388 & 117.914 & 401.215 & 246.418 & 98.071 & 745.703 \\
\hline 2016 & 172.199 & 72.523 & 111.517 & 356.239 & 202.088 & 94.776 & 653.103 \\
\hline 2017 & 155.162 & 63.992 & 105.768 & 324.922 & 213.458 & 97.750 & 636.131 \\
\hline
\end{tabular}

Elaboração dos autores. 
TABELA A. 2

Investimento líquido: formação líquida de capital fixo (1947-2017)

(Em R\$ milhões, a preços de 2010)

\begin{tabular}{|c|c|c|c|c|c|c|c|}
\hline & \multicolumn{4}{|c|}{ Construção } & \multirow{3}{*}{ Máquinas e equipamentos } & \multirow{3}{*}{ Outros } & \multirow{3}{*}{ Total } \\
\hline & \multirow{2}{*}{ Residencial } & \multicolumn{2}{|c|}{ Não residencial } & \multirow{2}{*}{ Total } & & & \\
\hline & & Infraestrutura & Demais estruturas & & & & \\
\hline 1947 & 4.920 & 2.868 & 4.684 & 12.472 & 5.110 & 235 & 17.817 \\
\hline 1948 & 5.608 & 4.854 & 1.392 & 11.853 & 3.575 & 222 & 15.650 \\
\hline 1949 & 6.307 & 5.000 & 3.518 & 14.825 & 3.894 & 43 & 18.762 \\
\hline 1950 & 4.976 & 6.081 & 4.487 & 15.545 & 4.877 & 502 & 20.923 \\
\hline 1951 & 9.010 & 6.093 & 7.297 & 22.400 & 10.083 & 255 & 32.738 \\
\hline 1952 & 8.708 & 5.987 & 9.247 & 23.941 & 9.467 & 389 & 33.797 \\
\hline 1953 & 10.354 & 5.911 & 12.692 & 28.957 & 963 & 281 & 30.201 \\
\hline 1954 & 11.562 & 6.777 & 10.730 & 29.070 & 10.254 & 496 & 39.820 \\
\hline 1955 & 9.947 & 3.920 & 10.990 & 24.858 & 4.658 & 667 & 30.183 \\
\hline 1956 & 12.413 & 5.162 & 13.460 & 31.035 & 3.515 & 522 & 35.072 \\
\hline 1957 & 12.996 & 9.562 & 9.519 & 32.077 & 8.843 & 803 & 41.724 \\
\hline 1958 & 17.049 & 14.322 & 10.546 & 41.917 & 7.764 & 633 & 50.314 \\
\hline 1959 & 18.592 & 11.698 & 16.350 & 46.640 & 12.309 & 646 & 59.595 \\
\hline 1960 & 19.784 & 16.336 & 14.074 & 50.194 & 12.029 & 802 & 63.025 \\
\hline 1961 & 13.469 & 15.896 & 5.450 & 34.816 & 10.293 & 941 & 46.049 \\
\hline 1962 & 21.935 & 19.285 & 13.708 & 54.929 & 13.278 & 1.104 & 69.311 \\
\hline 1963 & 23.899 & 15.621 & 16.950 & 56.470 & 13.914 & 1.157 & 71.541 \\
\hline 1964 & 22.385 & 15.187 & 14.796 & 52.368 & 8.590 & 898 & 61.855 \\
\hline 1965 & 21.183 & 17.740 & 8.768 & 47.691 & 2.788 & 1.307 & 51.786 \\
\hline 1966 & 22.586 & 12.542 & 17.930 & 53.058 & 15.513 & 815 & 69.386 \\
\hline 1967 & 22.520 & 13.000 & 17.390 & 52.910 & 13.011 & 1.070 & 66.991 \\
\hline 1968 & 26.328 & 12.081 & 28.527 & 66.936 & 24.563 & 913 & 92.412 \\
\hline 1969 & 28.229 & 27.273 & 21.366 & 76.867 & 28.044 & 838 & 105.750 \\
\hline 1970 & 32.955 & 31.434 & 24.748 & 89.137 & 22.461 & -1.652 & 109.946 \\
\hline 1971 & 39.581 & 27.873 & 38.050 & 105.505 & 28.049 & -1.007 & 132.547 \\
\hline 1972 & 45.487 & 28.730 & 51.604 & 125.821 & 35.025 & -345 & 160.502 \\
\hline 1973 & 54.234 & 29.442 & 72.615 & 156.291 & 48.802 & 483 & 205.576 \\
\hline 1974 & 61.184 & 48.271 & 68.158 & 177.613 & 57.419 & 1.046 & 236.077 \\
\hline 1975 & 66.419 & 48.082 & 78.474 & 192.976 & 62.507 & 1.434 & 256.917 \\
\hline 1976 & 71.238 & 88.555 & 49.395 & 209.188 & 60.579 & 5.912 & 275.679 \\
\hline 1977 & 68.977 & 71.582 & 61.113 & 201.672 & 46.388 & 9.340 & 257.400 \\
\hline 1978 & 74.191 & 68.441 & 74.014 & 216.646 & 41.903 & 13.661 & 272.209 \\
\hline 1979 & 76.351 & 53.478 & 91.051 & 220.880 & 33.078 & 17.302 & 271.260 \\
\hline 1980 & 89.685 & 47.164 & 124.479 & 261.328 & 40.153 & 24.087 & 325.568 \\
\hline 1981 & 75.047 & 36.138 & 98.514 & 209.700 & 20.049 & 14.043 & 243.792 \\
\hline
\end{tabular}




\begin{tabular}{|c|c|c|c|c|c|c|c|}
\hline & \multicolumn{4}{|c|}{ Construção } & \multirow{3}{*}{ Máquinas e equipamentos } & \multirow{3}{*}{ Outros } & \multirow{3}{*}{ Total } \\
\hline & \multirow{2}{*}{ Residencial } & \multicolumn{2}{|c|}{ Não residencial } & \multirow{2}{*}{ Total } & & & \\
\hline & & Infraestrutura & Demais estruturas & & & & \\
\hline 1982 & 65.307 & 33.065 & 80.855 & 179.227 & 11.563 & 7.656 & 198.446 \\
\hline 1983 & 53.989 & 25.147 & 52.249 & 131.385 & -4.718 & 2.080 & 128.747 \\
\hline 1984 & 50.207 & 17.463 & 53.227 & 120.897 & -7.009 & -825 & 113.062 \\
\hline 1985 & 56.765 & 23.414 & 60.671 & 140.850 & 5.611 & -1.815 & 144.646 \\
\hline 1986 & 80.099 & 36.136 & 86.973 & 203.207 & 30.097 & 1.669 & 234.973 \\
\hline 1987 & 75.988 & 33.287 & 81.469 & 190.744 & 20.183 & 1.339 & 212.266 \\
\hline 1988 & 68.048 & 29.270 & 73.075 & 170.393 & 13.498 & 673 & 184.564 \\
\hline 1989 & 67.884 & 13.001 & 88.295 & 169.180 & 18.374 & 1.005 & 188.559 \\
\hline 1990 & 54.571 & 17.711 & 59.465 & 131.747 & 3.739 & -813 & 134.673 \\
\hline 1991 & 50.736 & 14.327 & 52.687 & 117.750 & -4.406 & -639 & 112.705 \\
\hline 1992 & 44.635 & 17.775 & 34.593 & 97.003 & -10.127 & -81 & 86.796 \\
\hline 1993 & 50.798 & 10.285 & 44.182 & 105.264 & 285 & -5 & 104.975 \\
\hline 1994 & 59.439 & 10.547 & 47.288 & 117.274 & 30.808 & 1.606 & 149.688 \\
\hline 1995 & 70.789 & -1.053 & 66.571 & 136.308 & 68.784 & 3.369 & 208.461 \\
\hline 1996 & 71.569 & 7.463 & 53.281 & 132.313 & 42.285 & -3.260 & 171.338 \\
\hline 1997 & 79.886 & 3.257 & 60.310 & 143.454 & 50.593 & -2.627 & 191.419 \\
\hline 1998 & 79.515 & 28.831 & 34.057 & 142.404 & 34.184 & -3.079 & 173.509 \\
\hline 1999 & 75.006 & 6.827 & 54.487 & 136.320 & 5.561 & -686 & 141.195 \\
\hline 2000 & 47.942 & 16.332 & 42.544 & 106.819 & 34.463 & 35.748 & 177.030 \\
\hline 2001 & 42.561 & 18.646 & 40.334 & 101.541 & -1.226 & 30.136 & 130.451 \\
\hline 2002 & 42.088 & 7.293 & 48.297 & 97.678 & 4.872 & 22.619 & 125.169 \\
\hline 2003 & 41.435 & -1.975 & 34.475 & 73.936 & -2.937 & 22.757 & 93.755 \\
\hline 2004 & 43.051 & 12.480 & 33.947 & 89.477 & 15.320 & 20.768 & 125.565 \\
\hline 2005 & 36.344 & 6.423 & 39.373 & 82.140 & 13.177 & 21.096 & 116.414 \\
\hline 2006 & 38.119 & 11.923 & 34.053 & 84.096 & 33.468 & 19.669 & 137.233 \\
\hline 2007 & 42.693 & 22.039 & 36.546 & 101.279 & 70.996 & 20.558 & 192.832 \\
\hline 2008 & 42.886 & 26.896 & 48.733 & 118.514 & 105.989 & 20.631 & 245.134 \\
\hline 2009 & 50.828 & 43.852 & 31.053 & 125.733 & 61.288 & 18.492 & 205.513 \\
\hline 2010 & 64.000 & 53.304 & 39.859 & 157.163 & 130.083 & 18.632 & 305.879 \\
\hline 2011 & 71.690 & 58.192 & 41.491 & 171.373 & 123.255 & 19.225 & 313.853 \\
\hline 2012 & 85.653 & 63.548 & 32.287 & 181.488 & 86.702 & 11.550 & 279.739 \\
\hline 2013 & 92.007 & 61.968 & 32.162 & 186.137 & 101.601 & 5.661 & 293.398 \\
\hline 2014 & 81.549 & 53.395 & 35.670 & 170.614 & 57.646 & 1.170 & 229.431 \\
\hline 2015 & 67.922 & 24.782 & 18.050 & 110.754 & -25.335 & -7.366 & 78.053 \\
\hline 2016 & 48.024 & 1.334 & 5.656 & 55.014 & -65.158 & -9.649 & -19.793 \\
\hline 2017 & 29.561 & -7.560 & -7.485 & 14.516 & -44.544 & -5.843 & -35.870 \\
\hline
\end{tabular}


TABELA A.3

Estoque líquido de capital fixo (1947-2017)

(Em R\$ milhões, a preços de 2010)

\begin{tabular}{|c|c|c|c|c|c|c|c|}
\hline & \multicolumn{4}{|c|}{ Construção } & \multirow{3}{*}{ Máquinas e equipamentos } & \multirow{3}{*}{ Outros } & \multirow{3}{*}{ Total } \\
\hline & \multirow{2}{*}{ Residencial } & \multicolumn{2}{|c|}{ Não residencial } & \multirow{2}{*}{ Total } & & & \\
\hline & & Infraestrutura & Demais estruturas & & & & \\
\hline 1947 & 130.128 & 19.801 & 40.726 & 190.655 & 92.355 & 15.583 & 298.593 \\
\hline 1948 & 135.736 & 24.655 & 42.117 & 202.508 & 95.930 & 15.805 & 314.243 \\
\hline 1949 & 142.043 & 29.655 & 45.635 & 217.333 & 99.824 & 15.848 & 333.005 \\
\hline 1950 & 147.019 & 35.736 & 50.122 & 232.878 & 104.702 & 16.350 & 353.929 \\
\hline 1951 & 156.029 & 41.829 & 57.419 & 255.277 & 114.785 & 16.605 & 386.667 \\
\hline 1952 & 164.737 & 47.816 & 66.666 & 279.219 & 124.252 & 16.994 & 420.464 \\
\hline 1953 & 175.090 & 53.727 & 79.358 & 308.175 & 125.215 & 17.275 & 450.665 \\
\hline 1954 & 186.653 & 60.504 & 90.088 & 337.245 & 135.469 & 17.770 & 490.484 \\
\hline 1955 & 196.600 & 64.424 & 101.079 & 362.103 & 140.127 & 18.438 & 520.668 \\
\hline 1956 & 209.013 & 69.586 & 114.539 & 393.137 & 143.642 & 18.960 & 555.740 \\
\hline 1957 & 222.009 & 79.148 & 124.057 & 425.215 & 152.485 & 19.763 & 597.463 \\
\hline 1958 & 239.058 & 93.471 & 134.604 & 467.132 & 160.249 & 20.396 & 647.777 \\
\hline 1959 & 257.650 & 105.169 & 150.954 & 513.772 & 172.558 & 21.042 & 707.372 \\
\hline 1960 & 277.434 & 121.505 & 165.027 & 563.966 & 184.587 & 21.844 & 770.397 \\
\hline 1961 & 290.903 & 137.401 & 170.478 & 598.782 & 194.880 & 22.785 & 816.446 \\
\hline 1962 & 312.839 & 156.686 & 184.185 & 653.710 & 208.158 & 23.889 & 885.757 \\
\hline 1963 & 336.738 & 172.307 & 201.135 & 710.180 & 222.072 & 25.046 & 957.298 \\
\hline 1964 & 359.123 & 187.494 & 215.931 & 762.548 & 230.661 & 25.944 & 1.019 .153 \\
\hline 1965 & 380.306 & 205.235 & 224.699 & 810.239 & 233.449 & 27.251 & 1.070 .939 \\
\hline 1966 & 402.892 & 217.776 & 242.629 & 863.297 & 248.962 & 28.066 & 1.140 .325 \\
\hline 1967 & 425.412 & 230.776 & 260.018 & 916.207 & 261.973 & 29.136 & 1.207 .316 \\
\hline 1968 & 451.740 & 242.857 & 288.546 & 983.143 & 286.536 & 30.049 & 1.299 .727 \\
\hline 1969 & 479.969 & 270.130 & 309.912 & 1.060 .010 & 314.580 & 30.887 & 1.405 .477 \\
\hline 1970 & 512.923 & 301.564 & 334.660 & 1.149 .148 & 337.041 & 29.235 & 1.515 .423 \\
\hline 1971 & 552.504 & 329.438 & 372.710 & 1.254 .652 & 365.090 & 28.228 & 1.647 .970 \\
\hline 1972 & 597.991 & 358.168 & 424.315 & 1.380 .473 & 400.115 & 27.883 & 1.808 .472 \\
\hline 1973 & 652.225 & 387.609 & 496.930 & 1.536 .764 & 448.917 & 28.366 & 2.014 .047 \\
\hline 1974 & 713.409 & 435.880 & 565.088 & 1.714 .377 & 506.336 & 29.412 & 2.250 .124 \\
\hline 1975 & 779.828 & 483.963 & 643.563 & 1.907 .353 & 568.842 & 30.846 & 2.507 .042 \\
\hline 1976 & 851.066 & 572.518 & 692.957 & 2.116 .541 & 629.422 & 36.758 & 2.782 .720 \\
\hline 1977 & 920.043 & 644.100 & 754.070 & 2.318 .213 & 675.809 & 46.098 & 3.040 .121 \\
\hline 1978 & 994.233 & 712.542 & 828.085 & 2.534 .859 & 717.712 & 59.759 & 3.312 .330 \\
\hline 1979 & 1.070 .584 & 766.019 & 919.135 & 2.755 .739 & 750.790 & 77.061 & 3.583 .590 \\
\hline 1980 & 1.160 .269 & 813.183 & 1.043 .615 & 3.017 .067 & 790.943 & 101.148 & 3.909 .159 \\
\hline 1981 & 1.235 .317 & 849.321 & 1.142 .129 & 3.226 .767 & 810.992 & 115.191 & 4.152 .950 \\
\hline
\end{tabular}




\begin{tabular}{|c|c|c|c|c|c|c|c|}
\hline & \multicolumn{4}{|c|}{ Construção } & \multirow{3}{*}{ Máquinas e equipamentos } & \multirow{3}{*}{ Outros } & \multirow{3}{*}{ Total } \\
\hline & \multirow{2}{*}{ Residencial } & \multicolumn{2}{|c|}{ Não residencial } & \multirow{2}{*}{ Total } & & & \\
\hline & & Infraestrutura & Demais estruturas & & & & \\
\hline 1982 & 1.300 .624 & 882.386 & 1.222 .984 & 3.405 .994 & 822.555 & 122.848 & 4.351 .396 \\
\hline 1983 & 1.354 .612 & 907.533 & 1.275 .233 & 3.537.378 & 817.837 & 124.928 & 4.480 .143 \\
\hline 1984 & 1.404 .819 & 924.996 & 1.328 .461 & 3.658 .275 & 810.828 & 124.103 & 4.593 .205 \\
\hline 1985 & 1.461 .584 & 948.410 & 1.389 .132 & 3.799 .125 & 816.438 & 122.288 & 4.737 .851 \\
\hline 1986 & 1.541 .683 & 984.545 & 1.476 .105 & 4.002 .333 & 846.535 & 123.956 & 4.972 .824 \\
\hline 1987 & 1.617 .671 & 1.017 .832 & 1.557 .573 & 4.193.077 & 866.719 & 125.295 & 5.185 .090 \\
\hline 1988 & 1.685 .719 & 1.047 .102 & 1.630 .649 & 4.363 .470 & 880.217 & 125.968 & 5.369 .654 \\
\hline 1989 & 1.753 .603 & 1.060 .103 & 1.718 .943 & 4.532 .650 & 898.591 & 126.973 & 5.558 .214 \\
\hline 1990 & 1.808 .174 & 1.077 .814 & 1.778 .408 & 4.664 .396 & 902.331 & 126.160 & 5.692 .887 \\
\hline 1991 & 1.858 .910 & 1.092 .141 & 1.831 .095 & 4.782 .147 & 897.925 & 125.520 & 5.805 .592 \\
\hline 1992 & 1.903 .545 & 1.109 .916 & 1.865 .688 & 4.879 .150 & 887.798 & 125.440 & 5.892 .388 \\
\hline 1993 & 1.954 .343 & 1.120 .201 & 1.909 .870 & 4.984 .414 & 887.513 & 125.435 & 5.997 .363 \\
\hline 1994 & 2.013 .782 & 1.130 .748 & 1.957 .158 & 5.101 .688 & 918.322 & 127.041 & 6.147 .051 \\
\hline 1995 & 2.084 .572 & 1.129 .695 & 2.023 .730 & 5.237 .996 & 987.106 & 130.410 & 6.355 .512 \\
\hline 1996 & 2.156 .141 & 1.137.158 & 2.077 .011 & 5.370 .309 & 1.029 .390 & 127.150 & 6.526 .850 \\
\hline 1997 & 2.236 .027 & 1.140 .415 & 2.137 .321 & 5.513 .763 & 1.079 .983 & 124.523 & 6.718 .269 \\
\hline 1998 & 2.315 .542 & 1.169 .246 & 2.171 .379 & 5.656 .167 & 1.114 .167 & 121.445 & 6.891 .778 \\
\hline 1999 & 2.390 .547 & 1.176 .073 & 2.225 .866 & 5.792 .487 & 1.119 .728 & 120.758 & 7.032 .973 \\
\hline 2000 & 2.438 .490 & 1.192 .405 & 2.268 .410 & 5.899 .305 & 1.154 .191 & 156.506 & 7.210 .003 \\
\hline 2001 & 2.481 .050 & 1.211 .052 & 2.308 .744 & 6.000 .846 & 1.152 .966 & 186.642 & 7.340 .454 \\
\hline 2002 & 2.523 .139 & 1.218 .344 & 2.357 .041 & 6.098 .524 & 1.157 .838 & 209.261 & 7.465 .623 \\
\hline 2003 & 2.564 .574 & 1.216 .370 & 2.391 .517 & 6.172 .460 & 1.154 .901 & 232.018 & 7.559.378 \\
\hline 2004 & 2.607 .625 & 1.228 .849 & 2.425 .463 & 6.261 .937 & 1.170 .221 & 252.786 & 7.684.944 \\
\hline 2005 & 2.643 .969 & 1.235 .273 & 2.464 .836 & 6.344 .077 & 1.183 .398 & 273.882 & 7.801 .358 \\
\hline 2006 & 2.682 .088 & 1.247 .196 & 2.498 .889 & 6.428 .173 & 1.216 .867 & 293.551 & 7.938.591 \\
\hline 2007 & 2.724 .781 & 1.269 .235 & 2.535 .436 & 6.529 .452 & 1.287 .862 & 314.109 & 8.131 .423 \\
\hline 2008 & 2.767 .666 & 1.296 .131 & 2.584 .168 & 6.647 .966 & 1.393 .851 & 334.739 & 8.376 .557 \\
\hline 2009 & 2.818 .495 & 1.339 .983 & 2.615 .222 & 6.773 .699 & 1.455 .139 & 353.231 & 8.582 .070 \\
\hline 2010 & 2.882 .495 & 1.393 .287 & 2.655 .081 & 6.930 .863 & 1.585 .223 & 371.864 & 8.887.949 \\
\hline 2011 & 2.954 .185 & 1.451 .479 & 2.696 .571 & 7.102 .236 & 1.708 .477 & 391.089 & 9.201 .802 \\
\hline 2012 & 3.039 .838 & 1.515 .027 & 2.728 .858 & 7.283 .723 & 1.795 .179 & 402.639 & 9.481 .541 \\
\hline 2013 & 3.131 .845 & 1.576 .995 & 2.761 .020 & 7.469 .860 & 1.896 .780 & 408.300 & 9.774 .940 \\
\hline 2014 & 3.213 .394 & 1.630 .391 & 2.796 .690 & 7.640 .474 & 1.954 .426 & 409.470 & 10.004 .370 \\
\hline 2015 & 3.281 .316 & 1.655 .172 & 2.814 .740 & 7.751.228 & 1.929 .092 & 402.104 & 10.082 .423 \\
\hline 2016 & 3.329 .341 & 1.656 .506 & 2.820 .395 & 7.806 .242 & 1.863 .934 & 392.455 & 10.062 .631 \\
\hline 2017 & 3.358 .902 & 1.648 .946 & 2.812 .911 & 7.820 .758 & 1.819 .390 & 386.613 & 10.026 .761 \\
\hline
\end{tabular}

Elaboração dos autores. 
TABELA A.4

Relação capital/produto, por categoria - estoque de capital por categoria/produto interno bruto (PIB) (1947-2017)

\begin{tabular}{|c|c|c|c|c|c|c|c|}
\hline & \multirow{3}{*}{ Residencial } & \multicolumn{3}{|c|}{ Construção } & \multirow{3}{*}{ Máquinas e equipamentos } & \multirow{3}{*}{ Outros } & \multirow{3}{*}{ Total } \\
\hline & & \multicolumn{2}{|c|}{ Não residencial } & \multirow{2}{*}{ Total } & & & \\
\hline & & Infraestrutura & Demais estruturas & & & & \\
\hline 1947 & 0,775 & 0,118 & 0,243 & 1,136 & 0,550 & 0,093 & 1,779 \\
\hline 1948 & 0,737 & 0,134 & 0,229 & 1,100 & 0,521 & 0,086 & 1,706 \\
\hline 1949 & 0,716 & 0,150 & 0,230 & 1,096 & 0,503 & 0,080 & 1,679 \\
\hline 1950 & 0,694 & 0,169 & 0,237 & 1,099 & 0,494 & 0,077 & 1,671 \\
\hline 1951 & 0,702 & 0,188 & 0,258 & 1,149 & 0,517 & 0,075 & 1,740 \\
\hline 1952 & 0,691 & 0,201 & 0,280 & 1,171 & 0,521 & 0,071 & 1,764 \\
\hline 1953 & 0,701 & 0,215 & 0,318 & 1,235 & 0,502 & 0,069 & 1,805 \\
\hline 1954 & 0,694 & 0,225 & 0,335 & 1,253 & 0,503 & 0,066 & 1,823 \\
\hline 1955 & 0,672 & 0,220 & 0,345 & 1,237 & 0,479 & 0,063 & 1,778 \\
\hline 1956 & 0,694 & 0,231 & 0,380 & 1,305 & 0,477 & 0,063 & 1,845 \\
\hline 1957 & 0,684 & 0,244 & 0,382 & 1,311 & 0,470 & 0,061 & 1,841 \\
\hline 1958 & 0,665 & 0,260 & 0,374 & 1,299 & 0,446 & 0,057 & 1,802 \\
\hline 1959 & 0,653 & 0,266 & 0,382 & 1,302 & 0,437 & 0,053 & 1,792 \\
\hline 1960 & 0,642 & 0,281 & 0,382 & 1,306 & 0,427 & 0,051 & 1,784 \\
\hline 1961 & 0,620 & 0,293 & 0,364 & 1,277 & 0,416 & 0,049 & 1,741 \\
\hline 1962 & 0,626 & 0,313 & 0,368 & 1,308 & 0,416 & 0,048 & 1,772 \\
\hline 1963 & 0,670 & 0,343 & 0,400 & 1,412 & 0,442 & 0,050 & 1,903 \\
\hline 1964 & 0,691 & 0,361 & 0,415 & 1,466 & 0,444 & 0,050 & 1,960 \\
\hline 1965 & 0,714 & 0,385 & 0,422 & 1,522 & 0,438 & 0,051 & 2,011 \\
\hline 1966 & 0,709 & 0,383 & 0,427 & 1,519 & 0,438 & 0,049 & 2,007 \\
\hline 1967 & 0,719 & 0,390 & 0,439 & 1,548 & 0,442 & 0,049 & 2,039 \\
\hline 1968 & 0,695 & 0,374 & 0,444 & 1,512 & 0,441 & 0,046 & 1,999 \\
\hline 1969 & 0,674 & 0,379 & 0,435 & 1,489 & 0,442 & 0,043 & 1,974 \\
\hline 1970 & 0,653 & 0,384 & 0,426 & 1,462 & 0,429 & 0,037 & 1,928 \\
\hline 1971 & 0,631 & 0,377 & 0,426 & 1,434 & 0,417 & 0,032 & 1,883 \\
\hline 1972 & 0,611 & 0,366 & 0,433 & 1,409 & 0,409 & 0,028 & 1,846 \\
\hline 1973 & 0,584 & 0,347 & 0,445 & 1,377 & 0,402 & 0,025 & 1,804 \\
\hline 1974 & 0,591 & 0,361 & 0,468 & 1,420 & 0,419 & 0,024 & 1,864 \\
\hline 1975 & 0,614 & 0,381 & 0,507 & 1,502 & 0,448 & 0,024 & 1,975 \\
\hline 1976 & 0,608 & 0,409 & 0,495 & 1,512 & 0,450 & 0,026 & 1,988 \\
\hline 1977 & 0,626 & 0,438 & 0,513 & 1,578 & 0,460 & 0,031 & 2,070 \\
\hline 1978 & 0,645 & 0,462 & 0,537 & 1,644 & 0,465 & 0,039 & 2,148 \\
\hline 1979 & 0,650 & 0,465 & 0,558 & 1,674 & 0,456 & 0,047 & 2,177 \\
\hline 1980 & 0,645 & 0,452 & 0,581 & 1,678 & 0,440 & 0,056 & 2,175 \\
\hline 1981 & 0,718 & 0,493 & 0,664 & 1,875 & 0,471 & 0,067 & 2,413 \\
\hline 1982 & 0,749 & 0,508 & 0,705 & 1,962 & 0,474 & 0,071 & 2,507 \\
\hline & & & & & & & (Continua \\
\hline
\end{tabular}


Texto para

Discussão

Estoque de Capital Fixo no Brasil: séries desagregadas anuais, trimestrais e mensais

\begin{tabular}{|c|c|c|c|c|c|c|c|}
\hline & \multirow{3}{*}{ Residencial } & \multicolumn{3}{|c|}{ Construção } & \multirow{3}{*}{ Máquinas e equipamentos } & \multirow{3}{*}{ Outros } & \multirow{3}{*}{ Total } \\
\hline & & \multicolumn{2}{|c|}{ Não residencial } & \multirow{2}{*}{ Total } & & & \\
\hline & & Infraestrutura & Demais estruturas & & & & \\
\hline 1983 & 0,804 & 0,539 & 0,757 & 2,100 & 0,485 & 0,074 & 2,659 \\
\hline 1984 & 0,791 & 0,521 & 0,748 & 2,060 & 0,457 & 0,070 & 2,587 \\
\hline 1985 & 0,763 & 0,495 & 0,725 & 1,984 & 0,426 & 0,064 & 2,474 \\
\hline 1986 & 0,749 & 0,478 & 0,717 & 1,944 & 0,411 & 0,060 & 2,416 \\
\hline 1987 & 0,759 & 0,478 & 0,731 & 1,967 & 0,407 & 0,059 & 2,433 \\
\hline 1988 & 0,791 & 0,492 & 0,766 & 2,049 & 0,413 & 0,059 & 2,521 \\
\hline 1989 & 0,798 & 0,482 & 0,782 & 2,063 & 0,409 & 0,058 & 2,530 \\
\hline 1990 & 0,860 & 0,513 & 0,846 & 2,219 & 0,429 & 0,060 & 2,709 \\
\hline 1991 & 0,875 & 0,514 & 0,862 & 2,252 & 0,423 & 0,059 & 2,734 \\
\hline 1992 & 0,901 & 0,525 & 0,883 & 2,309 & 0,420 & 0,059 & 2,788 \\
\hline 1993 & 0,884 & 0,506 & 0,863 & 2,253 & 0,401 & 0,057 & 2,711 \\
\hline 1994 & 0,864 & 0,485 & 0,840 & 2,190 & 0,394 & 0,055 & 2,638 \\
\hline 1995 & 0,857 & 0,464 & 0,832 & 2,153 & 0,406 & 0,054 & 2,612 \\
\hline 1996 & 0,867 & 0,457 & 0,835 & 2,159 & 0,414 & 0,051 & 2,623 \\
\hline 1997 & 0,869 & 0,443 & 0,831 & 2,143 & 0,420 & 0,048 & 2,612 \\
\hline 1998 & 0,897 & 0,453 & 0,841 & 2,191 & 0,432 & 0,047 & 2,670 \\
\hline 1999 & 0,922 & 0,454 & 0,858 & 2,234 & 0,432 & 0,047 & 2,712 \\
\hline 2000 & 0,901 & 0,441 & 0,838 & 2,179 & 0,426 & 0,058 & 2,664 \\
\hline 2001 & 0,904 & 0,441 & 0,841 & 2,186 & 0,420 & 0,068 & 2,675 \\
\hline 2002 & 0,892 & 0,431 & 0,833 & 2,156 & 0,409 & 0,074 & 2,640 \\
\hline 2003 & 0,897 & 0,425 & 0,836 & 2,158 & 0,404 & 0,081 & 2,643 \\
\hline 2004 & 0,862 & 0,406 & 0,802 & 2,070 & 0,387 & 0,084 & 2,540 \\
\hline 2005 & 0,847 & 0,396 & 0,789 & 2,032 & 0,379 & 0,088 & 2,499 \\
\hline 2006 & 0,826 & 0,384 & 0,770 & 1,980 & 0,375 & 0,090 & 2,446 \\
\hline 2007 & 0,791 & 0,369 & 0,736 & 1,896 & 0,374 & 0,091 & 2,362 \\
\hline 2008 & 0,765 & 0,358 & 0,714 & 1,837 & 0,385 & 0,093 & 2,315 \\
\hline 2009 & 0,780 & 0,371 & 0,724 & 1,874 & 0,403 & 0,098 & 2,375 \\
\hline 2010 & 0,742 & 0,359 & 0,683 & 1,784 & 0,408 & 0,096 & 2,287 \\
\hline 2011 & 0,731 & 0,359 & 0,667 & 1,758 & 0,423 & 0,097 & 2,278 \\
\hline 2012 & 0,738 & 0,368 & 0,663 & 1,769 & 0,436 & 0,098 & 2,303 \\
\hline 2013 & 0,738 & 0,372 & 0,651 & 1,761 & 0,447 & 0,096 & 2,305 \\
\hline 2014 & 0,754 & 0,382 & 0,656 & 1,792 & 0,458 & 0,096 & 2,347 \\
\hline 2015 & 0,798 & 0,403 & 0,685 & 1,885 & 0,469 & 0,098 & 2,452 \\
\hline 2016 & 0,837 & 0,417 & 0,709 & 1,963 & 0,469 & 0,099 & 2,530 \\
\hline 2017 & 0,834 & 0,409 & 0,698 & 1,941 & 0,451 & 0,096 & 2,488 \\
\hline
\end{tabular}

Elaboração dos autores. 
TABELA A.5

Taxa implícita de depreciação, por categoria (1947-2017)

(Em \%)

\begin{tabular}{|c|c|c|c|c|c|c|c|}
\hline & \multirow{3}{*}{ Residencial } & \multicolumn{3}{|c|}{ Construção } & \multirow{3}{*}{ Máquinas e equipamentos } & \multirow{3}{*}{ Outros } & \multirow{3}{*}{ Total } \\
\hline & & \multicolumn{2}{|c|}{ Não residencial } & \multirow{2}{*}{ Total } & & & \\
\hline & & Infraestrutura & Demais estruturas & & & & \\
\hline 1947 & 3,22 & 4,70 & 2,65 & 3,25 & 14,58 & 14,80 & 7,40 \\
\hline 1948 & 3,29 & 5,08 & 2,43 & 3,29 & 13,53 & 14,90 & 7,07 \\
\hline 1949 & 3,32 & 5,02 & 2,49 & 3,35 & 12,79 & 15,11 & 6,83 \\
\hline 1950 & 3,40 & 4,94 & 2,56 & 3,44 & 12,73 & 15,03 & 6,78 \\
\hline 1951 & 3,37 & 4,79 & 2,88 & 3,48 & 12,90 & 15,46 & 6,82 \\
\hline 1952 & 3,52 & 4,84 & 2,08 & 3,41 & 13,17 & 15,59 & 6,83 \\
\hline 1953 & 3,67 & 4,71 & 2,18 & 3,50 & 13,45 & 14,97 & 6,90 \\
\hline 1954 & 3,16 & 4,68 & 2,27 & 3,19 & 13,37 & 15,21 & 6,48 \\
\hline 1955 & 3,12 & 4,58 & 2,35 & 3,18 & 13,51 & 14,67 & 6,45 \\
\hline 1956 & 3,17 & 4,63 & 2,23 & 3,17 & 13,32 & 14,75 & 6,31 \\
\hline 1957 & 3,03 & 4,87 & 2,29 & 3,14 & 13,14 & 14,73 & 6,12 \\
\hline 1958 & 2,97 & 4,97 & 2,19 & 3,12 & 12,81 & 14,78 & 5,98 \\
\hline 1959 & 3,13 & 4,67 & 2,16 & 3,16 & 12,99 & 15,01 & 5,96 \\
\hline 1960 & 3,04 & 4,67 & 2,12 & 3,10 & 12,83 & 14,76 & 5,82 \\
\hline 1961 & 3,08 & 4,55 & 2,38 & 3,19 & 13,41 & 14,72 & 5,96 \\
\hline 1962 & 3,28 & 4,56 & 2,44 & 3,33 & 13,31 & 14,55 & 6,03 \\
\hline 1963 & 3,09 & 4,41 & 2,36 & 3,20 & 12,84 & 14,79 & 5,78 \\
\hline 1964 & 3,12 & 4,40 & 2,43 & 3,24 & 12,94 & 14,62 & 5,79 \\
\hline 1965 & 3,18 & 4,44 & 2,58 & 3,32 & 13,15 & 14,69 & 5,83 \\
\hline 1966 & 3,21 & 4,29 & 2,60 & 3,31 & 13,07 & 14,50 & 5,72 \\
\hline 1967 & 3,24 & 4,30 & 2,60 & 3,33 & 13,03 & 14,63 & 5,73 \\
\hline 1968 & 3,28 & 4,22 & 2,47 & 3,29 & 13,05 & 14,65 & 5,68 \\
\hline 1969 & 3,33 & 4,44 & 2,24 & 3,28 & 13,19 & 14,57 & 5,73 \\
\hline 1970 & 3,22 & 4,45 & 2,17 & 3,22 & 13,15 & 14,71 & 5,70 \\
\hline 1971 & 3,06 & 4,38 & 2,17 & 3,15 & 13,60 & 14,74 & 5,70 \\
\hline 1972 & 3,06 & 4,34 & 2,21 & 3,14 & 14,18 & 14,77 & 5,79 \\
\hline 1973 & 3,08 & 4,33 & 2,19 & 3,13 & 14,18 & 14,71 & 5,75 \\
\hline 1974 & 3,14 & 4,47 & 2,18 & 3,16 & 14,07 & 14,51 & 5,75 \\
\hline 1975 & 3,15 & 4,42 & 2,30 & 3,19 & 13,91 & 14,21 & 5,75 \\
\hline 1976 & 3,12 & 4,65 & 2,03 & 3,14 & 13,54 & 13,82 & 5,63 \\
\hline 1977 & 3,10 & 4,46 & 2,13 & 3,15 & 13,37 & 13,12 & 5,60 \\
\hline 1978 & 3,12 & 4,40 & 2,16 & 3,17 & 13,62 & 12,87 & 5,64 \\
\hline 1979 & 3,10 & 4,29 & 2,24 & 3,15 & 13,72 & 12,38 & 5,61 \\
\hline 1980 & 3,09 & 4,24 & 2,22 & 3,12 & 13,78 & 12,25 & 5,55 \\
\hline 1981 & 3,07 & 4,19 & 2,29 & 3,10 & 13,52 & 12,07 & 5,44 \\
\hline 1982 & 3,12 & 4,16 & 2,37 & 3,13 & 13,22 & 11,98 & 5,34 \\
\hline 1983 & 3,07 & 4,13 & 2,43 & 3,12 & 12,96 & 11,20 & 5,20 \\
\hline & & & & & & & (Continua \\
\hline
\end{tabular}




\begin{tabular}{|c|c|c|c|c|c|c|c|}
\hline & \multicolumn{4}{|c|}{ Construção } & \multirow{3}{*}{ Máquinas e equipamentos } & \multirow{3}{*}{ Outros } & \multirow{3}{*}{ Total } \\
\hline & \multirow{2}{*}{ Residencial } & \multicolumn{2}{|c|}{ Não residencial } & \multirow{2}{*}{ Total } & & & \\
\hline & & Infraestrutura & Demais estruturas & & & & \\
\hline 1984 & 3,06 & 4,12 & 2,47 & 3,12 & 13,12 & 11,19 & 5,17 \\
\hline 1985 & 3,07 & 4,14 & 2,50 & 3,13 & 13,14 & 11,17 & 5,12 \\
\hline 1986 & 3,08 & 4,18 & 2,38 & 3,10 & 13,27 & 11,15 & 5,06 \\
\hline 1987 & 3,03 & 4,16 & 2,45 & 3,09 & 13,35 & 11,14 & 5,04 \\
\hline 1988 & 3,03 & 4,14 & 2,48 & 3,10 & 12,85 & 11,14 & 4,92 \\
\hline 1989 & 3,04 & 4,10 & 2,59 & 3,12 & 12,08 & 11,14 & 4,78 \\
\hline 1990 & 3,02 & 4,11 & 2,61 & 3,12 & 11,76 & 11,33 & 4,70 \\
\hline 1991 & 3,08 & 4,10 & 2,69 & 3,17 & 11,46 & 11,39 & 4,66 \\
\hline 1992 & 3,08 & 4,14 & 2,64 & 3,15 & 11,38 & 11,46 & 4,61 \\
\hline 1993 & 3,10 & 4,15 & 2,66 & 3,17 & 11,36 & 11,58 & 4,59 \\
\hline 1994 & 3,11 & 4,15 & 2,71 & 3,19 & 11,48 & 11,64 & 4,59 \\
\hline 1995 & 3,08 & 4,01 & 2,73 & 3,15 & 11,70 & 11,67 & 4,61 \\
\hline 1996 & 3,11 & 4,01 & 2,75 & 3,17 & 11,83 & 11,95 & 4,69 \\
\hline 1997 & 3,11 & 4,01 & 2,85 & 3,20 & 11,85 & 12,27 & 4,74 \\
\hline 1998 & 3,16 & 4,02 & 2,81 & 3,20 & 11,79 & 12,69 & 4,76 \\
\hline 1999 & 3,18 & 4,03 & 2,66 & 3,16 & 11,83 & 13,13 & 4,73 \\
\hline 2000 & 3,19 & 3,99 & 2,81 & 3,21 & 11,91 & 13,68 & 4,77 \\
\hline 2001 & 3,11 & 4,01 & 2,86 & 3,20 & 14,94 & 17,89 & 5,40 \\
\hline 2002 & 3,22 & 4,07 & 2,82 & 3,24 & 13,18 & 18,81 & 5,20 \\
\hline 2003 & 3,24 & 4,14 & 2,73 & 3,22 & 13,16 & 19,47 & 5,22 \\
\hline 2004 & 3,23 & 4,11 & 2,88 & 3,27 & 12,99 & 19,37 & 5,25 \\
\hline 2005 & 3,22 & 4,18 & 2,87 & 3,27 & 13,51 & 19,26 & 5,36 \\
\hline 2006 & 3,24 & 4,18 & 3,04 & 3,34 & 13,44 & 19,55 & 5,44 \\
\hline 2007 & 3,24 & 4,23 & 2,93 & 3,31 & 13,26 & 19,60 & 5,44 \\
\hline 2008 & 3,28 & 4,19 & 2,98 & 3,34 & 13,06 & 19,89 & 5,52 \\
\hline 2009 & 3,31 & 4,18 & 3,18 & 3,43 & 13,07 & 20,22 & 5,70 \\
\hline 2010 & 3,38 & 4,21 & 3,38 & 3,55 & 12,41 & 20,20 & 5,73 \\
\hline 2011 & 3,45 & 4,15 & 3,69 & 3,68 & 12,93 & 21,11 & 6,06 \\
\hline 2012 & 3,51 & 4,15 & 3,64 & 3,69 & 13,32 & 22,61 & 6,28 \\
\hline 2013 & 3,61 & 4,13 & 3,80 & 3,79 & 13,50 & 23,92 & 6,48 \\
\hline 2014 & 3,68 & 4,29 & 3,40 & 3,71 & 13,80 & 24,84 & 6,55 \\
\hline 2015 & 3,73 & 4,33 & 3,57 & 3,80 & 13,90 & 25,75 & 6,67 \\
\hline 2016 & 3,78 & 4,30 & 3,76 & 3,89 & 13,85 & 25,97 & 6,67 \\
\hline 2017 & 3,77 & 4,32 & 4,02 & 3,98 & 13,84 & 26,40 & 6,68 \\
\hline
\end{tabular}

Elaboração dos autores. 


\section{APÊNDICE B}

TABELA B. 1

Correspondências entre as taxas de depreciação do Bureau of Economic Analysis (BEA) e o Sistema de Contas Nacionais de 2010 (SCN 2010) nível divulgação

\begin{tabular}{|c|c|c|c|c|}
\hline \multicolumn{2}{|c|}{ Código e descrição SCN 2010 (nível divulgação - 128) } & \multirow{2}{*}{$\begin{array}{l}\text { Correspondência BEA } \\
\text { Food }\end{array}$} & \multirow{2}{*}{$\begin{array}{c}\begin{array}{c}\text { Taxa de } \\
\text { depreciação }\end{array} \\
0.0980\end{array}$} & \multirow{2}{*}{$\begin{array}{r}\text { Tempo } \\
\text { de vida } \\
20\end{array}$} \\
\hline 1917 & Laranja & & & \\
\hline 1918 & Café em grão & Food & 0.0980 & 20 \\
\hline 1919 & Outros produtos da lavoura permanente & Food & 0.0980 & 20 \\
\hline 1921 & $\begin{array}{l}\text { Bovinos e outros animais vivos, produtos animal, } \\
\text { caça e serviços }\end{array}$ & Food & 0.0980 & 20 \\
\hline 1923 & Suínos & Food & 0.0980 & 20 \\
\hline 1924 & Aves e ovos & Food & 0.0980 & 20 \\
\hline 2801 & Produtos da exploração florestal e da silvicultura & Wood products & 0.1633 & 12 \\
\hline \multirow{3}{*}{6801} & \multirow{3}{*}{ Petróleo, gás natural e serviços de apoio } & \multicolumn{2}{|l|}{ Mining exploration, shafts and wells } & \\
\hline & & Petroleum and natural gas (before 1973) & 0.0563 & 16 \\
\hline & & Petroleum and natural gas (1973 and later years) & 0.0751 & 12 \\
\hline 16001 & Produtos de madeira, exclusive móveis & Wood products & 0.1633 & 12 \\
\hline 24912 & $\begin{array}{l}\text { Semiacabados, laminados planos, longos e tubos } \\
\text { de aço }\end{array}$ & Fabricated metal products & 0.0680 & 24 \\
\hline 25001 & $\begin{array}{l}\text { Produtos de metal, exclusive máquinas } \\
\text { e equipamentos }\end{array}$ & Other fabricated metal products & 0.0917 & 18 \\
\hline 26002 & $\begin{array}{l}\text { Máquinas para escritório e equipamento } \\
\text { de informática }\end{array}$ & Computer and eletronic products & 0.1225 & 14 \\
\hline 26003 & $\begin{array}{l}\text { Material eletrônico e equipamento } \\
\text { de comunicações }\end{array}$ & Eletronic equipment, appliances, and components & 0.1225 & 14 \\
\hline 26004 & $\begin{array}{l}\text { Equipamento de medida, teste e controle, ópticos } \\
\text { e eletromédicos }\end{array}$ & Electromedical equipment /5/ & 0.1834 & 9 \\
\hline 27001 & Máquinas, aparelhos e materiais elétricos & Machinery & 0.0686 & 25 \\
\hline 27002 & Eletrodomésticos & Household appliances & 0.1500 & 11 \\
\hline 28001 & Tratores e outras máquinas agrícolas & Farm tractors & 0.1452 & 9 \\
\hline 28002 & Máquinas para a extração mineral e a construção & Construction machinery, except tractors & 0.1550 & 10 \\
\hline 28003 & Outras máquinas e equipamentos mecânicos & Other /4/ & 0.1473 & 11 \\
\hline \multirow{7}{*}{29911} & \multirow{7}{*}{ Automóveis, camionetas e utilitários } & Motor vehicles and parts & & \\
\hline & & Autos /12/ & & \\
\hline & & Trucks & & \\
\hline & & Years before 1992 /28/ & 0.2316 & 8 \\
\hline & & 1992 and later years /11/ & 0.1925 & 17 \\
\hline & & Recreational vehicles /28/ & 0.2316 & 8 \\
\hline & & Tires, tubes, accessories, and other parts /28/ & 0.6177 & 3 \\
\hline
\end{tabular}


Texto para

Discussão

2580 Estoque de Capital Fixo no Brasil: séries desagregadas anuais, trimestrais e mensais

(Continuação)

Código e descrição SCN 2010 (nivel divulgação - 128) C Correspondência BEA Tempo de Te

Trucks, buses, and truck trailers:

Years before 1992:

\begin{tabular}{lcc}
\hline Transit and ground passenger transportation /10/ & 0.1232 & 14 \\
\hline Trucking and other services /10/ & 0.1752 & 10 \\
\hline Other industries & 0.1917 & 9
\end{tabular}

29912 Caminhões e ônibus, inclusive cabines, carrocerias e reboques

1992 and later years:

$\begin{array}{lll}\text { Light trucks /11/ } & 0.1925 & 17\end{array}$

Other trucks, buses, and truck trailers:

\begin{tabular}{lcc}
\hline Transit and ground passenger transportation /10/ & 0.1232 & 14 \\
\hline Trucking and other services /10/ & 0.1725 & 10 \\
\hline Other industries & 0.1917 & 9 \\
\hline
\end{tabular}

Aircraft:

Years before 1960

Air transportation, depository inst

$0.1031 \quad 16$

intermediation, and depository institutions, other credit $\quad 0.1031$

$\begin{array}{lll}\text { Other industries } & 0.1375 & 12\end{array}$

30001 Aeronaves, embarcações e outros

1960 and later years:

equipamentos de transporte

Air transportation, depository institutions, other credit

intermediation, insurance agencies and brokers, offices of bank

holding companies and of other holding companies, funds,

trusts and other financial vehicles, and rental and leasing /11/

Other industries

\begin{tabular}{|c|c|c|c|c|}
\hline 31801 & Móveis & Furniture and related products & 0.1225 & 14 \\
\hline 31802 & Produtos de indústrias diversas & Other /4/ & 0.1473 & 11 \\
\hline 33001 & $\begin{array}{l}\text { Manutenção, reparação e instalação de } \\
\text { máquinas e equipamentos }\end{array}$ & Service industry machinery: other industries/14/ & 0.1500 & 11 \\
\hline \multirow{8}{*}{41801} & \multirow{7}{*}{ Edificações (residencial) } & $\begin{array}{l}\text { Residential capital (private and government) - except } \\
\text { residential capital services }\end{array}$ & 0.0293 & 42 \\
\hline & & 1-to-4-unit structures-new /21/ & 0.0114 & 80 \\
\hline & & 1-to-4-unit structures-major replacements /21/ & 0.0364 & 25 \\
\hline & & 5-or-more-unit structures-new /21/ & 0.0140 & 65 \\
\hline & & 5-or-more-unit structures-major replacements /21/ & 0.0455 & 20 \\
\hline & & Manufactured homes /21/ & 0.0455 & 20 \\
\hline & & Other structures /21/ & 0.0227 & 40 \\
\hline & Edificações (demais estruturas) & $\begin{array}{l}\text { Private nonresidential structures (except mining exploration, } \\
\text { shafts and wells) }\end{array}$ & 0.0248 & 38 \\
\hline 41802 & Obras de infraestrutura & Frishtak e Mourão & 0.0390 & 45 \\
\hline \multirow{3}{*}{41803} & \multirow{3}{*}{$\begin{array}{l}\text { Serviços especializados para construção } \\
\text { (residencial e não residencial) }\end{array}$} & Residential capital services & 0.0256 & 36 \\
\hline & & 1-to-4-unit structures-additions and alterations /21/ & 0.0227 & 40 \\
\hline & & 5-or-more-unit structures-additions and alterations /21/ & 0.0284 & 32 \\
\hline 62801 & $\begin{array}{l}\text { Desenvolvimento de sistemas e outros serviços } \\
\text { de informação }\end{array}$ & Computer software and accessories & 0.5500 & 3 \\
\hline 71801 & Pesquisa e desenvolvimento & Research and development /24/ & 0.2628 & - \\
\hline 71802 & Serviços de arquitetura e engenharia & Financial and real estate services & 0.1600 & - \\
\hline
\end{tabular}

Elaboração dos autores. 
TABELA B.2

Correspondências entre as taxas de depreciação do BEA e o SCN 2010 nível retropolação

\begin{tabular}{|c|c|c|c|c|}
\hline \multicolumn{2}{|c|}{ Código e descrição SCN 2010 (nível retropolação - 107) } & Correspondência BEA & $\begin{array}{c}\text { Taxa de } \\
\text { depreciação }\end{array}$ & $\begin{array}{l}\text { Tempo } \\
\text { de vida }\end{array}$ \\
\hline 10106 & Outros produtos e serviços da lavoura & Food & 0.0980 & 20 \\
\hline 10110 & Frutas cítricas & Food & 0.0980 & 20 \\
\hline 10111 & Café em grão & Food & 0.0980 & 20 \\
\hline 10112 & $\begin{array}{l}\text { Produtos da exploração florestal e } \\
\text { da silvicultura }\end{array}$ & Wood products & 0.1633 & 12 \\
\hline 10201 & Bovinos e outros animais vivos & Food & 0.0980 & 20 \\
\hline 10203 & Suínos vivos & Food & 0.0980 & 20 \\
\hline 10204 & Aves vivas & Food & 0.0980 & 20 \\
\hline \multirow{3}{*}{20101} & \multirow{3}{*}{ Petróleo e gás natural } & \multicolumn{3}{|l|}{ Mining exploration, shafts and wells } \\
\hline & & Petroleum and natural gas (before 1973) & 0.0563 & 16 \\
\hline & & Petroleum and natural gas (1973 and later years) & 0.0751 & 12 \\
\hline 30601 & Produtos de madeira - exclusive móveis & Wood products & 0.1633 & 12 \\
\hline 32301 & $\begin{array}{l}\text { Produtos de metal - exclusive máquinas } \\
\text { e equipamento }\end{array}$ & Other fabricated metal products & 0.0917 & 18 \\
\hline 32401 & Máquinas e equipamentos & Machinery & 0.0686 & 25 \\
\hline 32501 & Eletrodomésticos & Household appliances & 0.1500 & 11 \\
\hline 32601 & $\begin{array}{l}\text { Máquinas para escritório e equipamentos } \\
\text { de informática }\end{array}$ & Computer and eletronic products & 0.1225 & 14 \\
\hline 32701 & Máquinas, aparelhos e materiais elétricos & Machinery & 0.0686 & 25 \\
\hline 32801 & $\begin{array}{l}\text { Material eletrônico e equipamentos } \\
\text { de comunicações }\end{array}$ & Eletronic equipment, appliances, and components & 0.1225 & 14 \\
\hline 32901 & $\begin{array}{l}\text { Aparelhos/instrumentos médico-hospitalar, } \\
\text { de medida e óptico }\end{array}$ & Electromedical equipment /5/ & 0.1834 & 9 \\
\hline
\end{tabular}

Motor vehicles and parts

Autos /12/

$33001 \quad$ Automóveis, camionetas e utilitários

$$
\text { Trucks }
$$

\begin{tabular}{lcc}
\hline Years before $1992 / 28 /$ & 0.2316 & 8 \\
\hline 1992 and later years /11/ & 0.1925 & 17 \\
\hline Recreational vehicles /28/ & 0.2316 & 8 \\
\hline Tires, tubes, accessories, and other parts /28/ & 0.6177 & 3
\end{tabular}

Trucks, buses, and truck trailers:

Years before 1992 :

Transit and ground passenger transportation /10/ 0.1232

\begin{tabular}{ll} 
Transit and ground passenger transportation /10/ & 0.1232 \\
\hline Trucking and other services /10/ & 0.1752
\end{tabular}

$\begin{array}{lll}\text { Trucking and other services /10/ } & 0.1752 & 10\end{array}$

Other industries

0.1917

$33101 \quad$ Caminhões e ônibus

\begin{tabular}{llc}
\hline 1992 and later years: & & \\
\hline Light trucks /11/ & 0.1925 & 17 \\
\hline Other trucks, buses, and truck trailers: & & \\
\hline Transit and ground passenger transportation /10/ & 0.1232 & 14 \\
\hline Trucking and other services /10/ & 0.1725 & 10 \\
\hline Other industries & 0.1917 & 9 \\
\hline
\end{tabular}


Texto para

Discussão

2580 Estoque de Capital Fixo no Brasil: séries desagregadas anuais, trimestrais e mensais

(Continuação

\begin{tabular}{|c|c|c|c|c|}
\hline \multicolumn{2}{|c|}{ Código e descrição SCN 2010 (nível retropolação - 107) } & Correspondência BEA & $\begin{array}{c}\text { Taxa de } \\
\text { depreciação }\end{array}$ & $\begin{array}{l}\text { Tempo } \\
\text { de vida }\end{array}$ \\
\hline 33301 & Outros equipamentos de transporte & Other transportation equipment & 0.0971 & 17 \\
\hline 33401 & Móveis e produtos das indústrias diversas & Furniture and related products & 0.1225 & 14 \\
\hline \multirow{3}{*}{50101} & Construção (residencial) & Residential capital & 0.0283 & 40 \\
\hline & Construção (infraestrutura) & Frishtak e Mourão & 0.0390 & 45 \\
\hline & Construção (demais estruturas) & $\begin{array}{l}\text { Private nonresidential structures (except mining } \\
\text { exploration, shafts and wells) }\end{array}$ & 0.0248 & 38 \\
\hline 80101 & Serviços de informação & Computer software and accessories & 0.5500 & 3 \\
\hline 110301 & Serviços prestados às empresas & Financial and real estate services & 0.1600 & - \\
\hline
\end{tabular}

Elaboração dos autores. 
TABELA B. 3

Correspondências entre as taxas de depreciação do BEA e o Sistema de Contas Nacionais Consolidadas (SCNC) 1985

\begin{tabular}{|c|c|c|c|}
\hline SCNC & Correspondência BEA & $\begin{array}{c}\text { Taxa de } \\
\text { depreciação }\end{array}$ & $\begin{array}{l}\text { Tempo } \\
\text { de vida }\end{array}$ \\
\hline Bovinos e suínos & Food & 0.098 & 20 \\
\hline Outros produtos agropecuários & Food & 0.098 & 20 \\
\hline Produtos minerais não metálicos & Nonmetallic mineral products & 0,1032 & 19 \\
\hline Papel, celulose, papelão e artefatos & Paper products & 0,1225 & 16 \\
\hline Outros produtos metalúrgicos & Other fabricated metal products & 0.0917 & 18 \\
\hline Fabricação e manutenção de máquinas e equipamentos & Machinery & 0.0686 & 25 \\
\hline Tratores e máquinas de terraplanagem & Construction tractors /14/ & 0.1633 & 8 \\
\hline Material elétrico & Miscellaneous electrical equipment /5/ & 0.1834 & 9 \\
\hline Equipamentos eletrônicos & Eletronic equipment, appliances, and components & 0.1225 & 14 \\
\hline \multirow{18}{*}{ Automóveis, caminhões e ônibus } & \multicolumn{3}{|l|}{ Motor vehicles and parts } \\
\hline & \multicolumn{3}{|l|}{ Autos /12/ } \\
\hline & \multicolumn{3}{|l|}{ Trucks } \\
\hline & Years before 1992 /28/ & 0.2316 & 8 \\
\hline & 1992 and later years /11/ & 0.1925 & 17 \\
\hline & Recreational vehicles /28/ & 0.2316 & 8 \\
\hline & Tires, tubes, accessories, and other parts /28/ & 0.6177 & 3 \\
\hline & \multicolumn{3}{|l|}{ Trucks, buses, and truck trailers: } \\
\hline & \multicolumn{3}{|l|}{ Years before 1992: } \\
\hline & Transit and ground passenger transportation /10/ & 0.1232 & 14 \\
\hline & Trucking and other services /10/ & 0.1752 & 10 \\
\hline & Other industries & 0.1917 & 9 \\
\hline & \multicolumn{3}{|l|}{1992 and later years: } \\
\hline & Light trucks /11/ & 0.1925 & 17 \\
\hline & \multicolumn{3}{|l|}{ Other trucks, buses, and truck trailers: } \\
\hline & Transit and ground passenger transportation /10/ & 0.1232 & 14 \\
\hline & Trucking and other services /10/ & 0.1725 & 10 \\
\hline & Other industries & 0.1917 & 9 \\
\hline Outros veículos e peças & Other industries & 0.1917 & 9 \\
\hline Madeira e mobiliário & Furniture and related products & 0.1225 & 14 \\
\hline Outros produtos têxteis & Textile and textile product mills & 0.1031 & 16 \\
\hline Produtos diversos & Other /4/ & 0.1473 & 11 \\
\hline Construção (residencial) & Residential capital & 0.0283 & 40 \\
\hline Construção (infraestrutura) & Frishtak e Mourão & 0.0390 & 45 \\
\hline Construção (demais estruturas) & $\begin{array}{l}\text { Private nonresidential structures (except mining exploration, } \\
\text { shafts and wells) }\end{array}$ & 0.0248 & 38 \\
\hline Serviços prestados às empresas & Scientific research and development services & 0.16 & - \\
\hline Aluguel de imóveis & Brokers' commissions and other ownership transfer costs /26/ & 0.1375 & 12 \\
\hline
\end{tabular}

Elaboração dos autores. 
TABELA B.4

\section{Correspondências entre as taxas de depreciação do BEA e a matriz de relações} intersetoriais (MRI)

\begin{tabular}{|c|c|c|c|}
\hline Produto MRI - classificação Menezes e Ortega (1991) & Correspondência BEA & $\begin{array}{c}\text { Taxa de } \\
\text { depreciação }\end{array}$ & $\begin{array}{l}\text { Tempo } \\
\text { de vida }\end{array}$ \\
\hline Florestamento e formação de culturas permanentes & Food & 0.098 & 20 \\
\hline Artigos de vidro & Nonmetallic mineral products & 0.1032 & 19 \\
\hline Outros produtos de minerais não metálicos & Nonmetallic mineral products & 0.1032 & 19 \\
\hline Sucata de metal & Other fabricated metal products & 0.0917 & 18 \\
\hline Outros produtos metalúrgicos & Other fabricated metal products & 0.0917 & 18 \\
\hline Bombas hidráulicas, motores, máquinas e equipamentos agrícolas & Farm tractors & 0.1452 & 9 \\
\hline Peças para máquinas & Other /4/ & 0.1473 & 11 \\
\hline Máquinas, aparelhos, equipamentos e instalações industriais & Machinery & 0.0686 & 25 \\
\hline $\begin{array}{l}\text { Máquinas para escritório e aparelhos eletrônicos para uso comercial, } \\
\text { industrial e terapêutico }\end{array}$ & Electromedical equipment /5/ & 0.1834 & 9 \\
\hline Geladeiras e aparelhos eletrodomésticos & Household appliances & 0.15 & 11 \\
\hline Tratores e máquinas rodoviárias, inclusive peças e acessórios & Construction machinery, except tractors & 0.155 & 10 \\
\hline Motores e aparelhos para produção e distribuição de energia elétrica & Machinery & 0.0686 & 25 \\
\hline Condutores elétricos & Miscellaneous electrical equipment /5/ & 0.1834 & 9 \\
\hline Material elétrico, inclusive para veículos & Eletronic equipment, appliances, and components & 0.1225 & 14 \\
\hline Material e equipamento eletrônico, inclusive comunicação & Eletronic equipment, appliances, and components & 0.1225 & 14 \\
\hline TV, rádios, toca-discos e semelhantes & Household appliances & 0.15 & 11 \\
\hline Automóveis, utilitários, caminhões e ônibus & Motor vehicles and parts & 0.1906 & 10 \\
\hline Motores e peças mecânicas para veículos & Other transportation equipment & 0.0971 & 17 \\
\hline Embarcações, inclusive motores, peças e acessórios & Machinery & 0.0686 & 25 \\
\hline Veículos ferroviários, inclusive peças e acessórios & Machinery & 0.0686 & 25 \\
\hline Outros veículos, peças e acessórios & Other transportation equipment & 0.0971 & 17 \\
\hline Móveis e artigos de colchoaria & Furniture and related products & 0.1225 & 14 \\
\hline Embalagens e outros produtos de matéria plástica & Plastics and rubber products & 0.14 & 14 \\
\hline Artigos do vestuário de malhas, resíduos e outros produtos têxteis & Textile and textile product mills & 0.1031 & 16 \\
\hline Artigos do vestuário, exclusive malha & Textile and textile product mills & 0.1031 & 16 \\
\hline Jornais, livros e outros artigos impressos & Printing and related support activities & 0.1307 & 15 \\
\hline Produtos diversos & Other /4/ & 0.1473 & 11 \\
\hline Serviços industriais, ar vapor e água industriais & Service industry machinery: other industries /14/ & 0.15 & 11 \\
\hline Serviços de reparação industrial & Service industry machinery: other industries /14/ & 0.15 & 11 \\
\hline Construção (residencial) & Residential capital & 0.0283 & 40 \\
\hline Construção (infraestrutura) & Frishtak e Mourão & 0.0390 & 45 \\
\hline Construção (demais estruturas) & $\begin{array}{l}\text { Private nonresidential structures (except mining } \\
\text { exploration, shafts and wells) }\end{array}$ & 0.0248 & 38 \\
\hline Transporte de passageiros e carga e margem de distribuição & Other transportation equipment & 0.0971 & 17 \\
\hline Outros serviços & Financial and real estate services & 0.16 & - \\
\hline
\end{tabular}

Elaboração dos autores.

Nota: ${ }^{1}$ Menezes, A. C.; Ortega, J. A. Matrizes insumo-produto brasileiras 1970, 1975 e 1980: compatibilização de atividades e produtos - metodologia e resultados. Rio de Janeiro: Editora UFRJ, 1991. $72 \mathrm{p}$ 


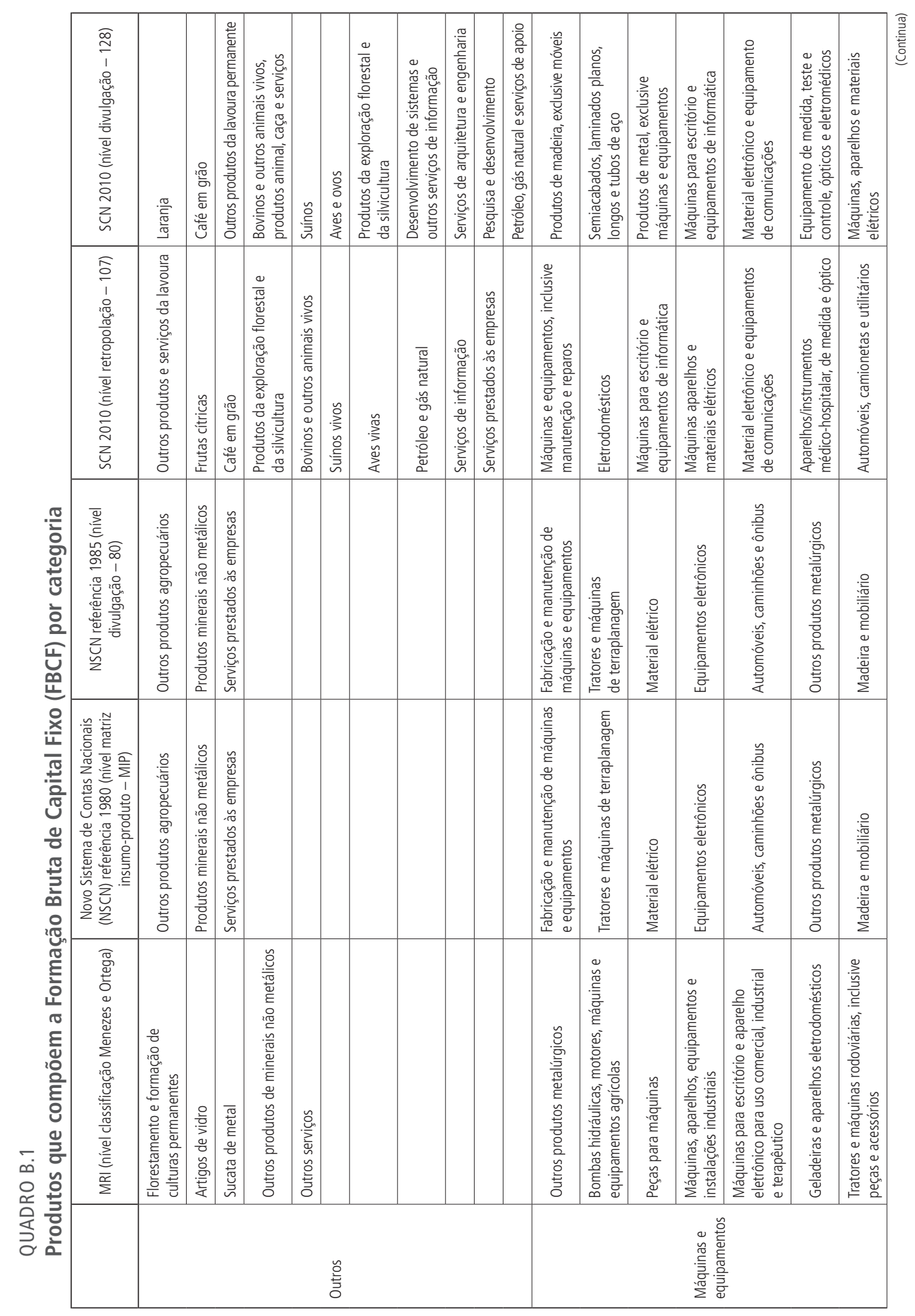

54 
2580 Estoque de Capital Fixo no Brasil: séries desagregadas anuais, trimestrais e mensais

\begin{tabular}{|c|c|c|c|c|c|c|c|c|c|c|c|c|c|c|c|c|c|c|c|}
\hline 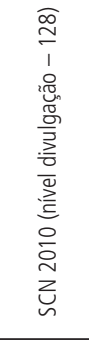 & 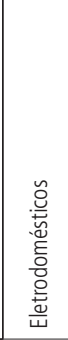 & 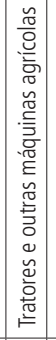 & 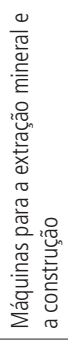 & 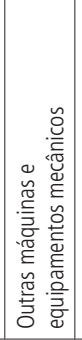 & 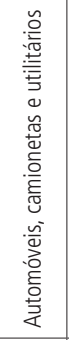 & 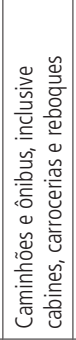 & 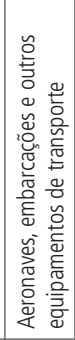 & 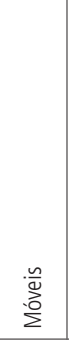 & 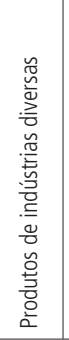 & 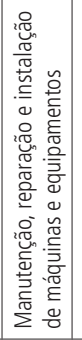 & & & & & & & 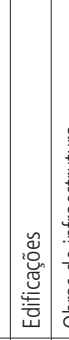 & 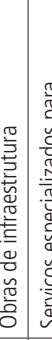 & 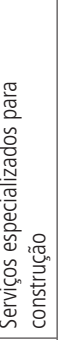 \\
\hline 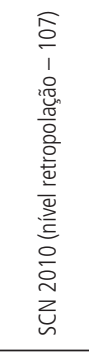 & 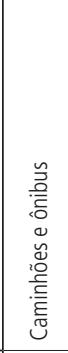 & 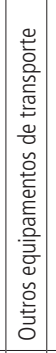 & 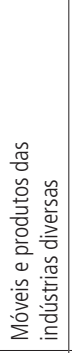 & 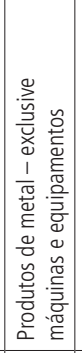 & 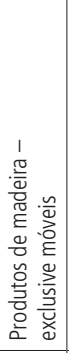 & & & & & & & & & & & & 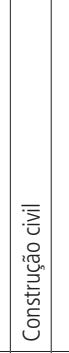 & & \\
\hline 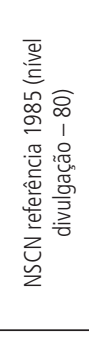 & 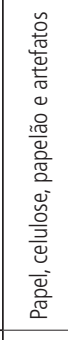 & 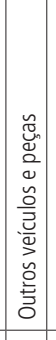 & 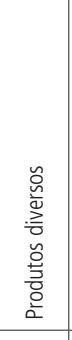 & & & & & & & & & & & & & & 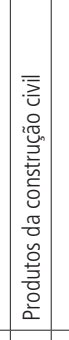 & & \\
\hline 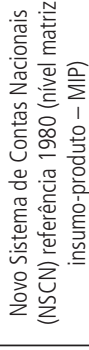 & 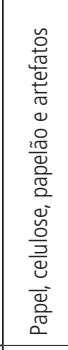 & 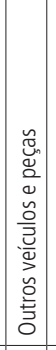 & 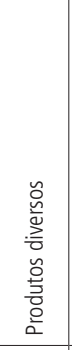 & 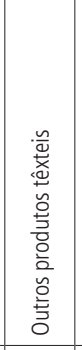 & & & & & & & & & & & & & 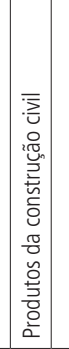 & & \\
\hline 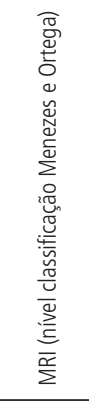 & 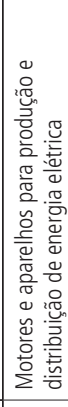 & 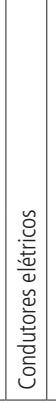 & 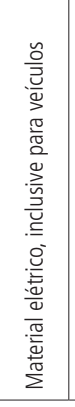 & 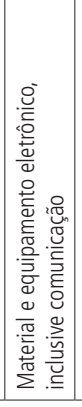 & 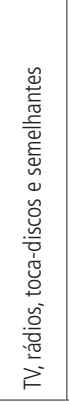 & 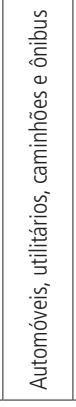 & 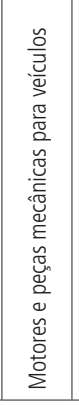 & 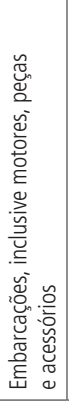 & 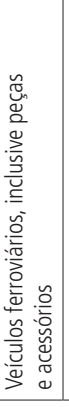 & 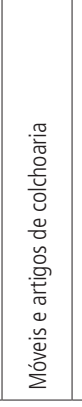 & 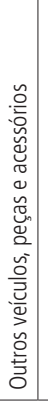 & 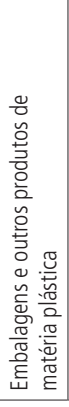 & 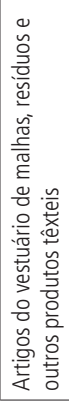 & 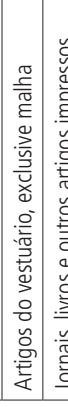 & 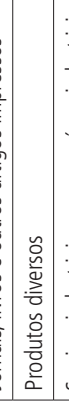 & 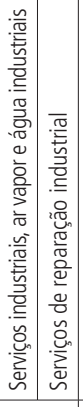 & 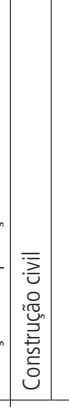 & & \\
\hline & & & & & & & & & & & & & & & & & & & \\
\hline
\end{tabular}


QUADRO B.2

Compatibilização FBCF referência 1985 e referência 2010 para a criação dos deflatores

\begin{tabular}{|c|c|c|}
\hline Código do produto nível 80 & Descrição do produto nível 80 - referência 1985 & Deflatores base 2010 - referência 2010 \\
\hline 199 & Outros produtos agropecuários & Outros produtos e serviços da lavoura \\
\hline 0401 & Produtos minerais não metálicos & Petróleo e gás natural \\
\hline 0701 & Outros produtos metalúrgicos & Produtos de metal - exclusive máquinas e equipamentos \\
\hline 0801 & Fabricação e manutenção de máquinas e equipamentos & \multirow{2}{*}{ Máquinas e equipamentos inclusive manutenção e reparos } \\
\hline 0802 & Tratores e máquinas terraplanagem & \\
\hline \multirow{2}{*}{1001} & \multirow{2}{*}{ Material elétrico } & Eletrodomésticos \\
\hline & & Máquinas, aparelhos e materiais elétricos \\
\hline \multirow{3}{*}{1101} & \multirow{3}{*}{ Equipamentos eletrônicos } & Máquinas para escritório e equipamentos de informática \\
\hline & & Material eletrônico e equipamentos de comunicações \\
\hline & & Aparelhos/instrumentos médico-hospitalar, de medida e óptico \\
\hline \multirow{2}{*}{1201} & \multirow{2}{*}{ Automóveis, caminhões e ônibus } & Automóveis, camionetas e utilitários \\
\hline & & Caminhões e ônibus \\
\hline 1301 & Outros veículos e peças & Outros equipamentos de transporte \\
\hline \multirow{2}{*}{1401} & \multirow{2}{*}{ Madeira e mobiliário } & Móveis e produtos das indústrias diversas \\
\hline & & Produtos de madeira - exclusive móveis \\
\hline 1501 & Papel, celulose, papelão e artefatos & Outros produtos e serviços da lavoura \\
\hline 3201 & Produtos diversos & Móveis e produtos das indústrias diversas \\
\hline 3401 & Produtos da construção civil & Construção civil \\
\hline \multirow{2}{*}{4001} & \multirow{2}{*}{ Serviços prestados a empresas } & Serviços de informação \\
\hline & & Serviços prestados às empresas \\
\hline
\end{tabular}

Elaboração dos autores. 
Texto para

Discussão

Estoque de Capital Fixo no Brasil: séries desagregadas anuais, trimestrais e mensais

\begin{tabular}{|c|c|c|c|c|c|c|c|}
\hline \multirow[t]{4}{*}{ 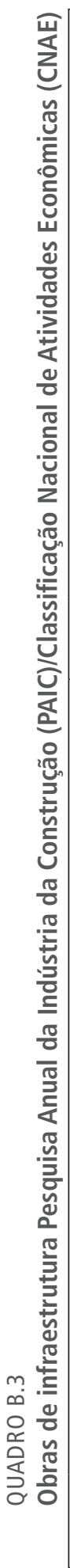 } & \multirow[t]{2}{*}{ 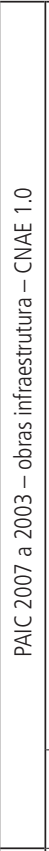 } & 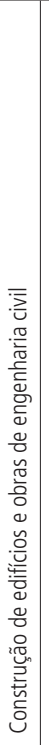 & \multicolumn{2}{|c|}{ 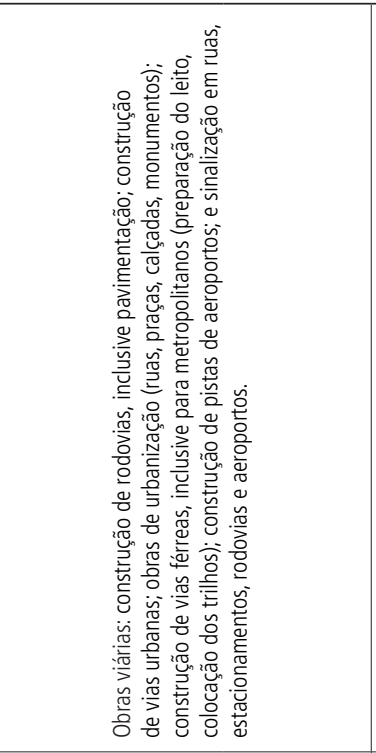 } & 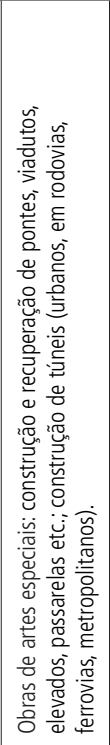 & 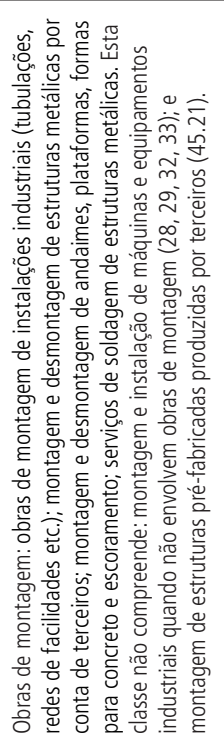 & 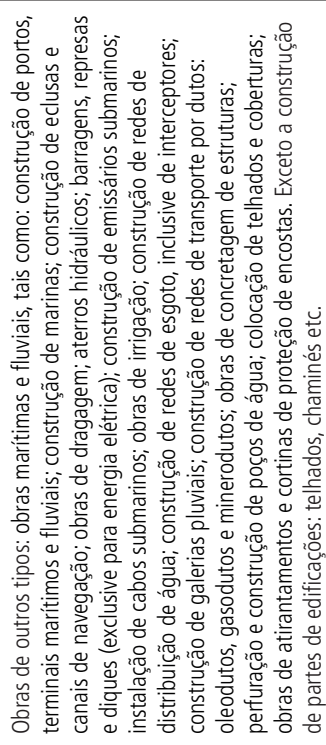 \\
\hline & & 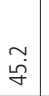 & \multicolumn{2}{|l|}{ 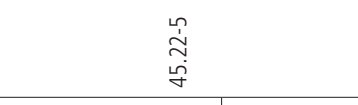 } & 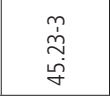 & 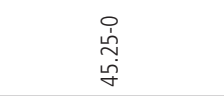 & 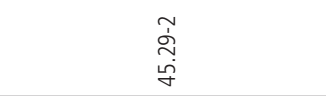 \\
\hline & 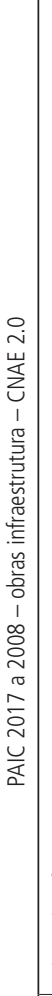 & 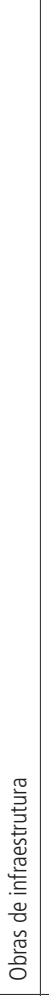 & 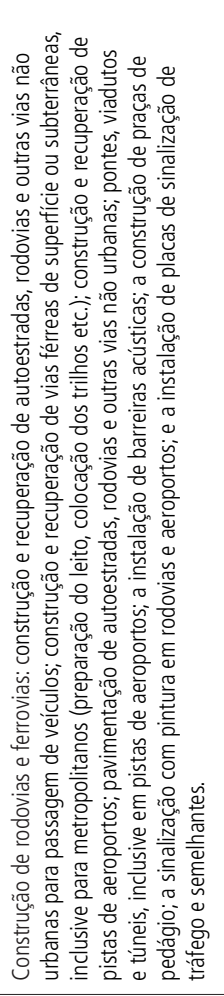 & 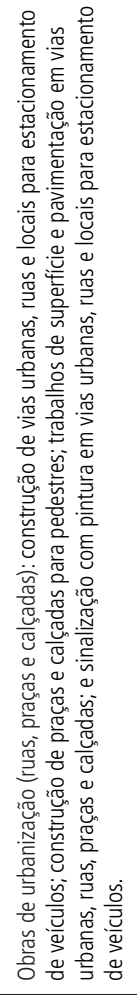 & 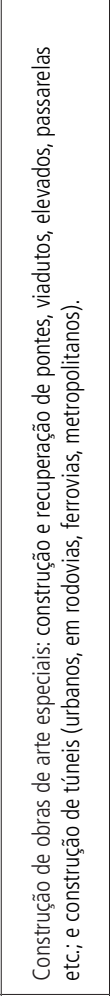 & 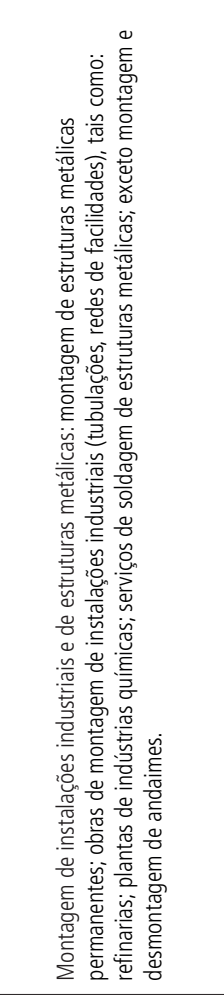 & 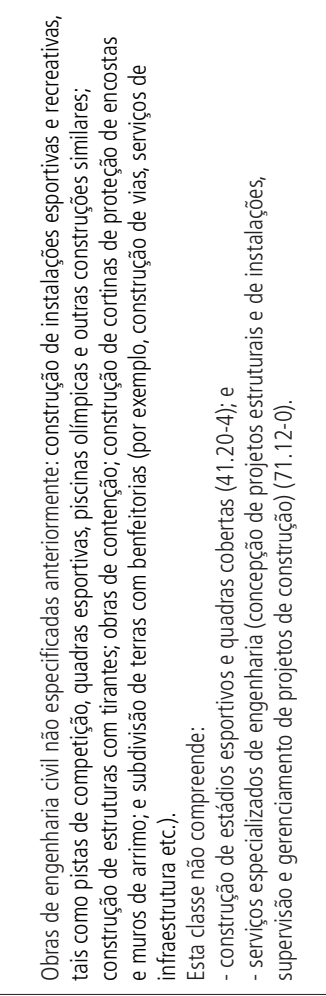 \\
\hline & & $\approx$ & 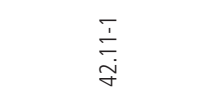 & 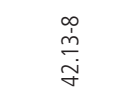 & 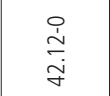 & $\stackrel{m}{\underset{F}{J}}$ & 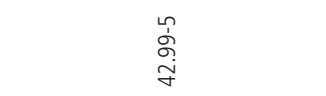 \\
\hline
\end{tabular}




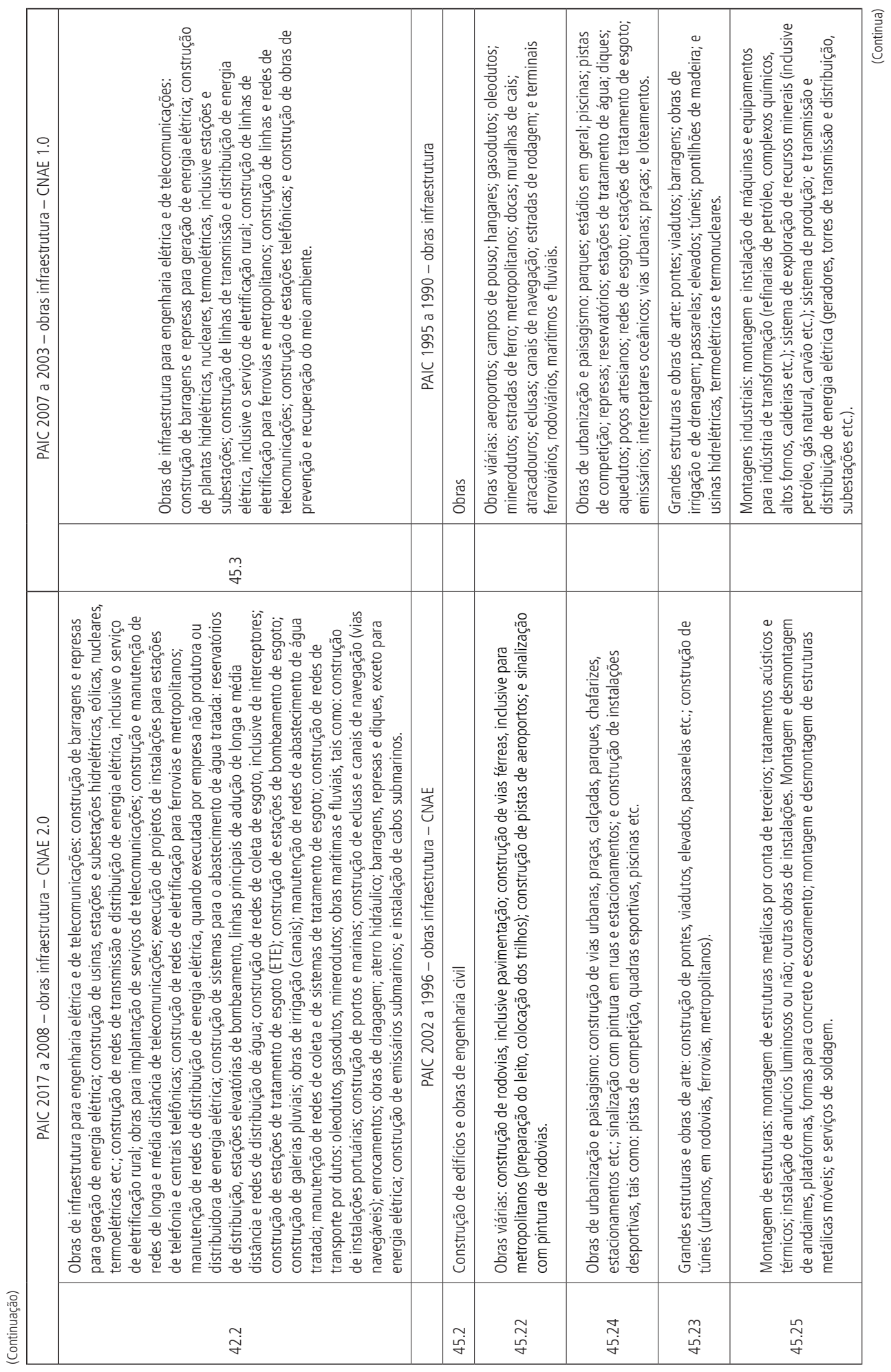

58 


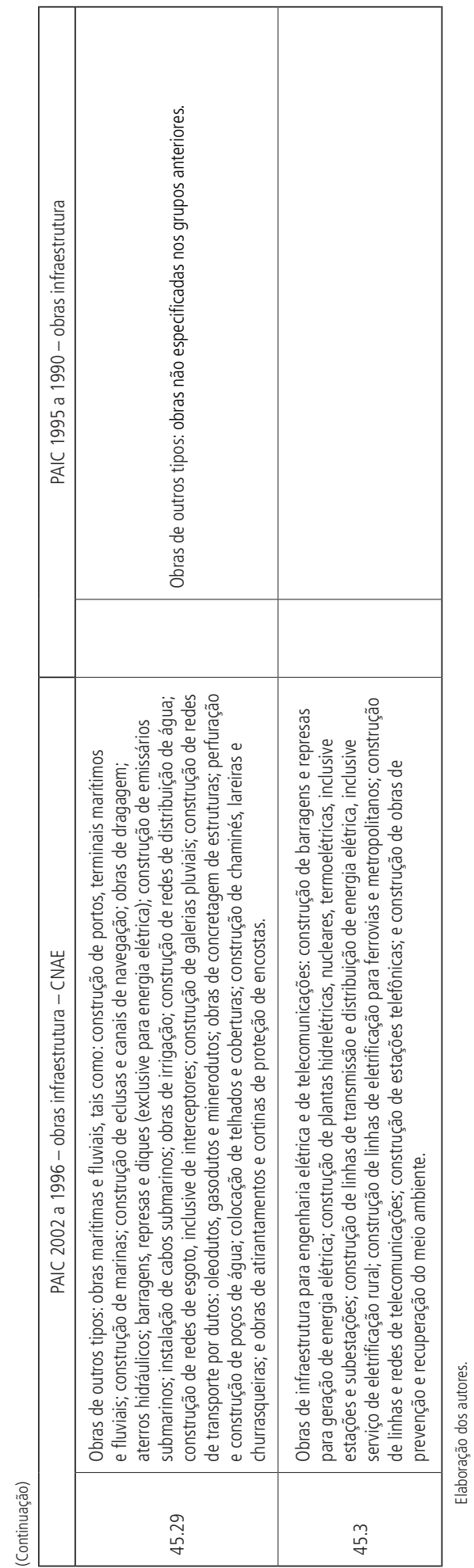




\section{APÊNDICE C}

Para obter uma estimativa do estoque de capital partindo de uma perspectiva multissetorial, devem ser buscadas informaçóes contidas nas tabelas de recursos e usos (TRUs), disponibilizadas pelo Instituto Brasileiro de Geografia e Estatística (IBGE).

As TRUs informam o valor da Formação Bruta de Capital Fixo (FBCF), tanto em valores correntes quanto em valores do ano anterior. No caso, temos:

$$
\begin{aligned}
& F B C F_{t, t}^{i}=P_{K, t}^{i} Q_{K, t}^{i} \\
& F B C F_{t, t-1}^{i}=P_{K, t-1}^{i} Q_{K, t}^{i}
\end{aligned}
$$

Em que o índice $i$ representa os setores e $P_{K, t}$ e $Q_{K, t}$ são, respectivamente, o preço e a quantidade de bens de capital demandados para investimentos realizados no período $t$.

Ao dividir as séries de FBCF em valor corrente pela de valor ao ano anterior, encontramos os fatores:

$$
\frac{P_{K, t}^{i}}{P_{K, t-1}^{i}}=1+\pi_{K, t}^{i}
$$

Em que $\pi_{K, t}^{i}$ é a taxa de inflação dos bens de capital. Subtraindo 1 e multiplicado por 100 , tem-se a variação percentual do nível de preço (taxa de inflação setorial). No caso, a série do deflator implícito:

$$
D I_{t}^{i}=\left(\frac{P_{t}^{i}}{P_{t-1}^{i}}-1\right) 100=\left(\frac{\Delta P_{t}^{i}}{P_{t-1}^{i}}\right) 100
$$

Feito isso, pode-se construir um número índice com a base em $t$ qualquer, de forma a aprimorar a comparação entre anos mais longos. $\mathrm{O}$ procedimento a ser 
realizado será o encadeamento das séries dos deflatores. ${ }^{1}$ Tomando por exemplo o ano-base em $t$, o encadeamento será da forma:

$$
D I_{t+n, t}^{i}=\left(\frac{P_{t+n}^{i}}{P_{t}^{i}}\right) 100=\left(\frac{P_{t+n}^{i}}{P_{t+n-1}^{i}} \frac{P_{t+n-1}^{i}}{P_{t+n-2}^{i}} \cdots \frac{P_{t+1}^{i}}{P_{t}^{i}}\right) 100
$$

Procedimento semelhante pode ser realizado para trás da série, no entanto, agora dividindo:

$$
D I_{t-n, t}^{i}=\left(\frac{P_{t-n}^{i}}{P_{t}^{i}}\right) 100=\left(\frac{\frac{P_{t-n+1}^{i}}{P_{t}^{i}}}{\frac{P_{t-n+1}^{i}}{P_{t-n}^{i}}}\right) 100
$$

Por fim, para extrair as séries deflacionadas, é necessário dividir a série da FBCF em valores correntes pela série de números-índice e multiplicar por 100:

$$
F B C F_{t, \text { preços constantes }}^{i}=\left(\frac{F B C F_{t, t}^{i}}{D_{t, t}^{i}}\right) 100
$$

1. Vale ressaltar que, a partir desse ponto, a propriedade de aditividade é perdida, ou seja, a série agregada não poderá mais ser obtida pela soma das séries. 
Ipea - Instituto de Pesquisa Econômica Aplicada

Assessoria de Imprensa e Comunicação

\title{
EDITORIAL
}

\section{Coordenação}

Reginaldo da Silva Domingos

\section{Supervisão}

Carlos Henrique Santos Vianna

\author{
Revisão \\ Bruna Oliveira Ranquine da Rocha \\ Carlos Eduardo Gonçalves de Melo \\ Elaine Oliveira Couto \\ Lis Silva Hall \\ Mariana Silva de Lima \\ Marlon Magno Abreu de Carvalho \\ Vivian Barros Volotão Santos \\ Laysa Martins Barbosa Lima (estagiária)

\section{Editoração} \\ Aline Cristine Torres da Silva Martins \\ Mayana Mendes de Mattos \\ Louise de Freitas Sarmento (estagiária)
}

\section{Capa}

Danielle de Oliveira Ayres

Flaviane Dias de Sant'ana

\section{Projeto Gráfico}

Renato Rodrigues Bueno

The manuscripts in languages other than Portuguese published herein have not been proofread.

\section{Livraria Ipea}

SBS - Quadra 1 - Bloco J - Ed. BNDES, Térreo.

70076-900 - Brasília - DF

Fone: (61) 2026-5336

Correio eletrônico: livraria@ipea.gov.br 


Composto em adobe garamond pro 12/16 (texto)
Frutiger 67 bold condensed (títulos, gráficos e tabelas) Rio de Janeiro-RJ 



\section{Missão do Ipea}

Aprimorar as políticas públicas essenciais ao desenvolvimento brasileiro por meio da produção e disseminação de conhecimentos e da assessoria ao Estado nas suas decisões estratégicas.

\section{ipea matumateramien Económica Aplicada}

MINISTÉRIO DA

ECONOMIA

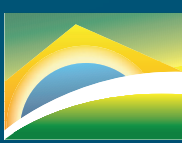

PÁTRIA AMADA BRASIL

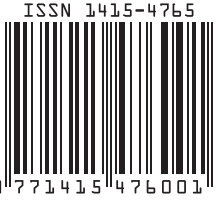

